Revista Calidad en la Educación Superior

Programa de Autoevaluación Académica

Universidad Estatal a Distancia, Costa Rica

ISSN 1659-4703

revistacalidad@uned.ac.cr

\title{
TRABAJO COLABORATIVO ENTRE ESTUDIANTES POR MEDIO DE UNA PLATAFORMA TECNOLÓGICA
}

COLLABORATIVE WORK OF STUDENTS THROUGH A TECHNOLOGY PLATFORM

Eduardo Jirón Fajardo ${ }^{1}$ ejiron@uned.ac.cr Universidad Estatal a Distancia, Costa Rica

\author{
Volumen 7, Número 1 \\ Mayo 2016 \\ pp. 1 - 52
}

Recibido: 10 octubre del 2015

Aprobado: 26 de febrero del 2016

\footnotetext{
${ }^{1}$ Eduardo Jirón Fajardo. Encargado de la Cátedra de Producción Escuela Ciencias de la Administración, Universidad Estatal a Distancia, Costa Rica. Correo electrónico: ejiron@uned.ac.cr
} 


\section{Resumen}

Poner en práctica las habilidades blandas para un estudiante de administración es necesario, y en un modelo de estudio a distancia, se debe procurar generar los espacios formativos para facilitar su desarrollo. Es posible lograr esas experiencias por medio de las plataformas tecnológicas que pueden coadyuvar para fomentar el trabajo colaborativo entre estudiantes, a la vez que también aprenden. En el presente documento se comparten las experiencias acerca de una actividad donde se logra generar las interacciones anteriormente señalada por medio de una plataforma tecnológica en modo asincrónico.

La actividad está contemplada en el modelo de evaluación de una asignatura que es parte de distintos planes de carrera relacionados con administración de empresas. Se diseñó para que cada estudiante se integre con sus pares a resolver diversas situaciones atinentes a objetivos de la asignatura y tratando de emular interacciones similares al mundo de los negocios empresariales.

Si bien hay variaciones metodológicas utilizadas en algunos períodos, la idea general es que cada estudiante por medio de la plataforma tecnológica en uso, interactúen jugando roles específicos como negociadores para los intereses propios de cada una de sus empresas, hasta lograr determinados objetivos pre-establecidos en las instrucciones de la actividad.

Entre los resultados observados está el hecho de los distintos grados de coordinación que logran los equipos a lo interno de cada espacio virtual y la variedad de compromisos que muestran distintos estudiantes. Interesante observar cuando un equipo logra una identidad propia y se observa el esfuerzo en generar valor agregado en las acciones para alcanzar las metas previstas.

Palabras clave: Trabajo colaborativo, aprendizaje colaborativo, actividades en plataformas, aprender a distancia, aprender colaborando, colaboración a distancia, plataformas de aprendizaje.

\section{Summary:}

Implement the soft skills for a student management is necessary, and in a model of distance learning, should seek to generate training spaces to facilitate their development. Those experiences can be achieved through technology platforms that can contribute to promote collaborative work among students, while also learning. In this document the experiences of an activity where it is possible to generate the interactions previously identified by means of a technology platform in asynchronous mode are shared.

The activity is covered by the assessment model of a subject that is part of different career plans related to business administration. It was designed for each student to integrate with their peers to solve various situations pertaining objectives of the course and trying to emulate similar interactions to the business real world.

While there are methodological variations used in some periods, the general idea is that each student through the technology platform in use, interacts playing specific roles as negotiators for the specific interests of each of its companies to achieve certain pre-established goals in the instructions for the activity.

Different degrees of coordination could be observed into the teams that manage internally in each virtual space, on the other hand, the variety of commitments that show different students. Interesting when a team achieves its own identity and effort to generate added value in the actions to achieve the goals envisaged observed. 


\section{Objetivo}

Compartir las experiencias que han tenido los estudiantes de la asignatura Compras y Almacenamientos (cód. 438) en el desarrollo de una actividad de tipo colaborativo entre pares por medio de una plataforma tecnológica.

El alcance de lo que se describirá acerca de la experiencia será en función del período desde que se inició este tipo de actividad hasta el último cuatrimestre en que se ha realizado la misma.

Lo anterior delimitado por el proceso de oferta académica que tiene la institución, lo cual implica que la asignatura está activa para impartirse ciertos cuatrimestres y también está la limitante de información que se basa sobre las evidencia recogidas de los medios (plataformas tecnológicas) donde ha sido desarrollada la actividad en línea en modalidad asincrónica; así como la experiencias misma del escritor quién ha diseñado, planificado, participado y supervisado la ejecución de la actividad.

\section{Justificación}

Este tipo de experiencias son importantes en el desarrollo de habilidades blandas para un estudiante de administración de negocios a pesar que se encuentre en un modelo de estudio a distancia.

Las interacciones se dan en el contexto de negociaciones, simulándose empresas, donde el estudiante pondrá en evidencia, además del dominio práctico de conocimiento previamente estudiado; también podrán exponer sus cualidades de liderazgo, trabajo bajo presión, interacción con pares en una temática típica del área de compras de una organización.

Las competencias que se requieren para un exitoso desempeño en el área de compras como parte del mundo empresarial, pueden ser promovidas a los estudiantes de administración que se están formando. Además de evaluarles en la aplicación práctica de ciertos conocimientos teóricos, también esta experiencia les brinda la oportunidad de que puedan ellos percibir si les falta aprender o no ciertas habilidades a ser empleadas en su futuro profesional. 
La idea de compartir esto con otros docentes, es casualmente visualizar que a pesar del modelo a distancia, hay experiencias por medio de las plataformas tecnológicas (PT) que pueden coadyuvar para fomentar el aprendizaje colaborativo en competencias de interacción que requiere el estudiante en formación.

\section{Marco contextual}

La característica de los estudiantes participantes en la asignatura "Compras y Almacenamiento" es común a los estudiantes de la Escuela de Ciencias de la Administración (ECA) de la Universidad Estatal a Distancia (UNED), ya que es una asignatura de servicio que inicialmente estaba, entre 2008 a 2014 en los planes de estudio anteriores al 2013 (no vigentes), de las carreras de administración de empresa con énfasis en producción, dirección de empresas y mercadeo en todo el territorio nacional.

Adicionalmente, desde el año 2013, la carrera de Administración en Servicios de la Salud de la Escuela de Ciencias Exactas y Naturales (ECEN), tomó entre otras asignaturas para su plan vigente de estudios, la asignatura Compras y Almacenamientos. Actualmente en 2015, dicha asignatura es cursada por estudiantes de la precitada carrera de la ECEN y por parte de la ECA, solamente quienes estudian la carrera de administración con énfasis en producción.

La precitada asignatura regularmente se ha ofertado una vez por año (en el 3er cuatrimestre), excepto en 2014 que se ofertó en 2 do y 3er cuatrimestre. La matrícula en promedio ha sido de 89 estudiantes, oscilando entre 64 a 131 estudiantes por cuatrimestre con una aprobación que también varía. Además, al estimar el promedio ponderado para dicho período, se obtiene un 66.1\% A continuación en el Cuadro 1 puede verse el detalle de oferta del 2008 al 2014 y el porcentaje de aprobación para la asignatura bajo estudio.

Cuadro 1: Matrícula y \% Aprobados en asignatura 438

\begin{tabular}{|l|l|l|l|l|l|l|l|l|}
\hline & 2008_5 & 2009_5 & 2010_5 & 2011_5 & 2012_5 & 2013_5 & 2014_4 & 2014_5 \\
\hline Matrícula & 73 & 84 & 81 & 105 & 106 & 131 & 71 & 64 \\
\hline \% éxito & $56 \%$ & $65 \%$ & $53 \%$ & $73 \%$ & $49 \%$ & $86 \%$ & $76 \%$ & $61 \%$ \\
\hline
\end{tabular}

Fuente: Elaboración propia 
Tomando como referencia el modelo de evaluación de la asignatura desde el año 2008 a la fecha, se muestra la evolución de dicho modelo como parte de un aspecto medular por medio del cual se establece la estructura para medir el aprendizaje de los estudiantes.

Cuadro 2: Modelos de evaluación en asignatura 438

\begin{tabular}{|c|c|c|c|c|c|c|c|c|}
\hline $\begin{array}{l}\text { Rubros } \\
\text { "modelo" }\end{array}$ & $2008^{*}$ & 2009* & 2010 & 2011 & 2012 & 2013 & 2014_2 & 2014_3 \\
\hline Ord. 1 & $35 \%$ & $30 \%$ & $25 \%$ & $25 \%$ & $25 \%$ & $25 \%$ & $25 \%$ & $25 \%$ \\
\hline Ord. 2 & $35 \%$ & $30 \%$ & $25 \%$ & $25 \%$ & $25 \%$ & $25 \%$ & $25 \%$ & $25 \%$ \\
\hline Tarea & $5 \%(A)$ & $\begin{array}{l}10 \% \\
\text { (A) }\end{array}$ & & & & & & \\
\hline Foros & $5 \%(B)$ & $\begin{array}{l}10 \% \\
\text { (B) }\end{array}$ & & & & & & \\
\hline $\begin{array}{l}\text { Actividades } \\
\text { en Línea (2) }\end{array}$ & & & $\begin{array}{l}15 \% \\
(2 \times 7.5 \%)\end{array}$ & $\begin{array}{l}15 \% \\
(2 \times 7.5 \%)\end{array}$ & $\begin{array}{l}15 \% \\
(2 \times 7.5 \%)\end{array}$ & $\begin{array}{l}15 \% \\
(2 \times 7.5 \%)\end{array}$ & $\begin{array}{l}15 \% \\
(2 \times 7.5 \%)\end{array}$ & $\begin{array}{l}15 \% \\
(2 \times 7.5 \%)\end{array}$ \\
\hline Proyecto & $25 \%$ & $30 \%$ & $35 \%$ & $35 \%$ & $35 \%$ & $35 \%$ & $35 \%$ & $35 \%$ \\
\hline PAL & WebCT & WebCT & BbLearn & BbLearn & BbLearn & BbLearn & BbLearn & BbLearn \\
\hline
\end{tabular}

*Estudiante elegía entre opciones A o B.

Fuente: Elaboración propia

Se fue incorporando el uso de foros como actividad evaluativa opcional, esto con el objetivo de ir alineándose con los cambios tecnológicos que venía dando la UNED para un mayor uso de las plataformas. Paulatinamente, se incrementó el porcentaje asignado a dichas evaluaciones y para 2010 se probó, como un piloto, lo que sería el modelo de evaluación del rediseño de la asignatura, listo para implementar en firme a partir del 2011.

En el rediseño mencionado, se estableció la modalidad de "actividad en línea" para así, dar flexibilidad de cambiar las actividades por realizar que podrían ser foro, blog, wiki u otra. Además, se hace un balance del esfuerzo individual y grupal con pesos iguales del 50\%; siendo en las pruebas escritas, donde queda la medición del conocimiento aprendido bajo un constructivismo cognitivo, ya que ahí se mide el resultado de un proceso individual; este "tiene lugar en la mente de las personas que es donde se encuentran almacenadas sus representaciones del mundo" (Serrano \& Pons, 2011, p.6). 
Por otra parte, se favorecen los procesos basados en un constructivismo social por medio de las actividades en línea y también con el proyecto por realizarse en una empresa, lo cual ya venía desarrollándose desde 2008; siendo respectivamente $15 \%$ y $35 \%$ sus pesos en la evaluación global de los aprendizajes de esta asignatura. Vemos entonces, que un balance de evaluación es importante sobre todo si se considera que el otro 50\% para medir el conocimiento de aprendizaje se basa en un trabajo grupal.

A como está estructurado el modelo de evaluación actual, podemos ver como los procesos de aprendizaje individual, donde "el elemento social ocupa un papel de coadyuvante a la mejora en la adquisición de los conocimientos, pero no es una condición necesaria para su construcción" (p.5), luego son retomados al momento que el estudiante realiza aprendizaje grupal.

Estos cambios progresivos que se fueron implementando en las experiencias de aprendizaje de los estudiantes, obedecen a la naturaleza en que se desempeñan las funciones de un gerente que dirige un área de compras o suministro. Por lo tanto, era preciso facilitar un contexto tal, para construir conocimiento, que además favoreciera el desarrollo de competencias que un profesional de la administración requiere para desempañarse exitosamente en el contexto laboral.

Entre 2008 y 2010 el proyecto era opcional realizarlo de manera individual o grupal grupal. A partir del año 2011, es obligatorio realizar en grupos (mínimo 2 integrantes) el proyecto y las actividades en línea.

Lo anterior considerando que un profesional del área de compras siempre está realizando trabajo en equipo con personas, tanto a lo interno del área de compras o suministros como de otras áreas de la organización y también con profesionales externos a su compañía. Además, un gerente laborando en dicha área, debe integrar en un mismo equipo de trabajo a personas dentro y fuera de su empresa para gestionar diversos procesos procurando la creación de valor. 


\section{Marco teórico}

¿Qué se entiende por aprendizaje colaborativo? Si bien hay muchos autores que pueden explicar el término, aquí se define como:

"El conjunto de métodos de instrucción y entrenamiento apoyados con tecnología así como de estrategias para propiciar el desarrollo de habilidades mixtas (aprendizaje y desarrollo personal y social), donde cada miembro del grupo es responsable tanto de su aprendizaje como del de los restantes miembros del grupo" (Lucero, 2003, p.4).

Dado que la actividad bajo análisis se realiza por medio de una plataforma tecnológica, donde se trata que el estudiante aprenda construyendo conocimiento en conjunto con sus pares, a la vez que se enfrenta a una situación típica de negocios, debe resolver los problemas y alcanzar los objetivos requeridos con frecuentes interacciones sociales.

También vale rescatar otro término, ya que se está utilizando el concepto de apoyarse en la tecnología para realizar trabajo con ciertos objetivos concretos en aspectos didácticos; esto es Groupware que Lloyd, (1994, citado en Vega, 2005, p.79) lo define así: "Procesos intencionales de un grupo para alcanzar objetivos específicos más herramientas de software diseñadas para dar soporte y facilitar el trabajo". Vega continúa diciendo que "se hace referencia a objetivos específicos de la organización, pues se trata de una estrategia que pretende coordinar actividades de: comunicación, colaboración, coordinación y negociación con el fin de aumentar la productividad" (p. 79).

Con la herramienta que se utiliza y la estructura de la actividad se facilita el aprendizaje colaborativo. A como se indica:

El aprendizaje en ambientes colaborativos busca propiciar espacios en los cuales se dé la discusión entre los estudiantes al momento de explorar conceptos que interesa dilucidar o situaciones problemáticas que se desea resolver; se busca que la combinación de situaciones e interacciones sociales pueda contribuir hacia un aprendizaje personal y grupal efectivo. (Lucero, 2003, p.4) 
Esto es precisamente lo que sucede en la actividad en línea NEGOCIACIONES, donde el estudiante va experimentando procesos similares que se presentan en un área de compras de una empresa y que aprende a resolver en un ambiente de colaboración, donde cada compañero aporta de alguna manera su propio conocimiento y a la vez que construyen el colectivo.

En la actividad precitada, se presentan los elementos básicos para fomentar el aprendizaje colaborativo que son:

Interdependencia positiva: Este es el elemento central; abarca las condiciones organizacionales y de funcionamiento que deben darse al interior del grupo. Los miembros del grupo deben necesitarse los unos a los otros y confiar en el entendimiento y éxito de cada persona; considera aspectos de interdependencia en el establecimiento de metas, tareas, recursos, roles, premios.

Interacción: Las formas de interacción y de intercambio verbal entre las personas del grupo, movidas por la interdependencia positiva. Son las que afectan los resultados de aprendizaje. El contacto permite realizar el seguimiento y el intercambio entre los diferentes miembros del grupo; el alumno aprende de ese compañero con el que interactúa día a día, o él mismo le puede enseñar, cabe apoyarse y apoyar. En la medida en que se posean diferentes medios de interacción, el grupo podrá enriquecerse, aumentar sus refuerzos y retroalimentarse.

Contribución individual: Cada miembro del grupo debe asumir íntegramente su tarea y, además, tener los espacios para compartirla con el grupo y recibir sus contribuciones.

Habilidades personales y de grupo: La vivencia del grupo debe permitir a cada miembro de éste el desarrollo y potencialización de sus habilidades personales; de igual forma, permitir el crecimiento del grupo y la obtención de habilidades grupales como: escucha, participación, liderazgo, coordinación de actividades, seguimiento y evaluación. (p.4)

Además, se ha de considerar diversos elementos para implementar el aprendizaje colaborativo citados a continuación: 
Control de las interacciones colaborativas: estructuración de las tareas, utilización de sistemas de comunicación asincrónicos y sincrónicos entre los estudiantes y el profesorado.

Dominios de aprendizaje colaborativo: planificación, categorización y distribución de las tareas.

Tareas en el aprendizaje colaborativo: análisis y resolución de problemas.

Diseño de entornos colaborativos de aprendizaje: trabajo en equipo, espacio de trabajo basado en la autorización.

Roles en el entorno colaborativo: tamaño del grupo, formas de participación, distribución de roles (el rol de cada estudiante puede cambiar durante el proceso de aprendizaje).

Autorización en el aprendizaje colaborativo: autorización entre iguales, aprendizaje a través de la negociación, etc." (Martín, Domínguez \& Paralera, 2011, p.3)

Se ha empleado el término plataforma tecnológica y de manera abreviada como PT, vale la pena retomar lo indicado por el Programa de Apoyo Curricular y Evaluación de los AprendizajesPACE (2014) en su Glosario; "plataforma tecnológica" es:

una plataforma -con carácter informático-, es precisamente el principio, en el cual se constituye un hardware, sobre el cual un software puede ejecutarse o desarrollarse y los sistemas de gestión de aprendizaje (Learning Management Systems) son programas (aplicación de software) instalados en un servidor; sin embargo, indistintamente, también se utiliza el término «plataforma» para denominar a estos últimos, por ejemplo: WebCT, Moodle, Micro Campus, BlackboardLearn, entre otros (PAL-PACE-UNED, 2011, 13). (p.63)

En la actividad se utiliza como base el modelo de negociación de las ocho fases. Conforme con lo que indica Ovejero (2004), este modelo se origina como resultado del análisis entre empresas y representantes sindicales del sector industrial al negociar ( $p .121)$ A pesar de ello, se 
consideró muy apropiado para los procesos de negociar con los proveedores, dado que en cierta manera están en el mismo barco como socios estratégicos.

La metodología utilizada consiste en descomponer el proceso de la negociación en ocho etapas, véase figura 1 (en pág.12), sin que necesariamente deban seguirse estrictamente en el orden indicado a continuación.

\section{Preparación}

Esta constituye la primera etapa para llegar a una negociación, buscando como asegurar el éxito. Se definen los aspectos por conseguir y la manera de lograrlo. En esta 1a. Fase se han de concretar los siguientes elementos; a saber:

- Objetivos: fundamentales, hay que establecerles prioridades tanto a los nuestros como a los del opositor. Así se inicia en la mesa de negociación con una idea clara de lo que se pretende conseguir.

-Información: se debe investigar suficiente para recopilar elementos que aporten oportunidades para negociar. La información ha de ser veraz, igualmente, se selecciona lo que se está dispuesto a compartir con la otra parte.

- Estrategias: se ha de establecer el plan de acción por seguir para las metas previstas en la negociación y tomar en consideración las posibles formas que puede adoptar una negociación. La estrategia debe ser firme, pero con cierta flexibilidad, y contingencias para acomodarse o reaccionar a los acuerdos que puedan surgir durante el curso de la negociación.

-Tareas: en negociaciones grupales cada quién debe tener claro su rol, pues resulta complejo hablar, escuchar, pensar, escribir, observar y planear al mismo tiempo. Las tareas esenciales son tres: dirección, síntesis y observación. Si alguien está solo, ha de asumir estas a lo largo de la negociación; cuando hay dos personas, el mismo que sintetiza observará y dejará al otro con el papel de director.

\section{Discusión}


Esto significa que las dos partes participan en una conversación. Esta etapa nos proporciona acceso a todo tipo de información sobre los objetivos, compromisos e intenciones del opositor; y su finalidad es que se dé una conversación intermedia. Lo mejor es escuchar al interlocutor, mientras más hable, más información de sus objetivos, compromisos e intenciones lograremos saber.

En síntesis, se debe lograr discusiones constructivas, tratando de hacer que esta etapa favorezca para llegar a nuestros objetivos. Un buen manejo de la discusión contribuye a mejorar las capacidades de negociadores.

\section{Las señales}

Una manera de facilitar acuerdo entre las partes es que cada uno realice movimientos para aproximarse. Al estar en una negociación, se requiere saber manejar las concesiones, para ello, es preciso contar con la habilidad para leer los mensajes o señales.

Las señales son mensajes para ser respondidos, preferiblemente luego de una correcta interpretación. En esta etapa hay que escuchar para lograr darse cuenta del mensaje de la otra parte, o podría ser que la interpretemos equívocamente.

\section{Las propuestas}

Esta parte es clave en la negociación, pues son las que se van a negociar por ambas partes, ya que cada una lleva sus propuestas. Son ofertas o peticiones diferentes a la proposición inicial, pues surgen de la etapa de discusión o conversación. En buena medida, se conforman a partir de las respuestas de un negociador o lo que ha aprendido de su opositor a través de la discusión y de las señales de este.

\section{$\underline{5 . ~ E l ~ p a q u e t e ~}$}

Este consiste en una actividad que responde a la apertura que hay durante la negociación. Ahí se establece el temario (un programa o lista de temas de negociación).

Entre otros aspectos diversos autores señalan como elementos básicos a considerar: 1) dirigir el paquete a los intereses e inhibiciones de la otra parte; 2) pensar creativamente en todas las 
posibles alternativas y 3) valorar nuestras concesiones, pues lo que nuestro opositor nos pida en una negociación es porque ha de tener un valor, aunque sea pequeño para nosotros, puede ser un valor inmenso para la otra parte. Kennedy y cols, (1986, citado en Ovejero, 2004, p.127)

Por eso, debemos valorar el paquete desde la posición del otro y no solo desde la nuestra. Recuerde que este conduce a la negociación hacia el terreno del intercambio, por lo que ha de favorecerse.

\section{El intercambio}

Como su nombre lo indica, se trata de obtener a cambio de entregar: cedemos y adquirimos. La regla más importante para la etapa de intercambio es que toda propuesta o concesión sea condicional. Es decir, no debe darse nada gratis. Es la regla del gran SI (si usted acepta esto, nosotros lo otro).

Figura 1: Esquema del modelo de Negociación de las OCHO FASES
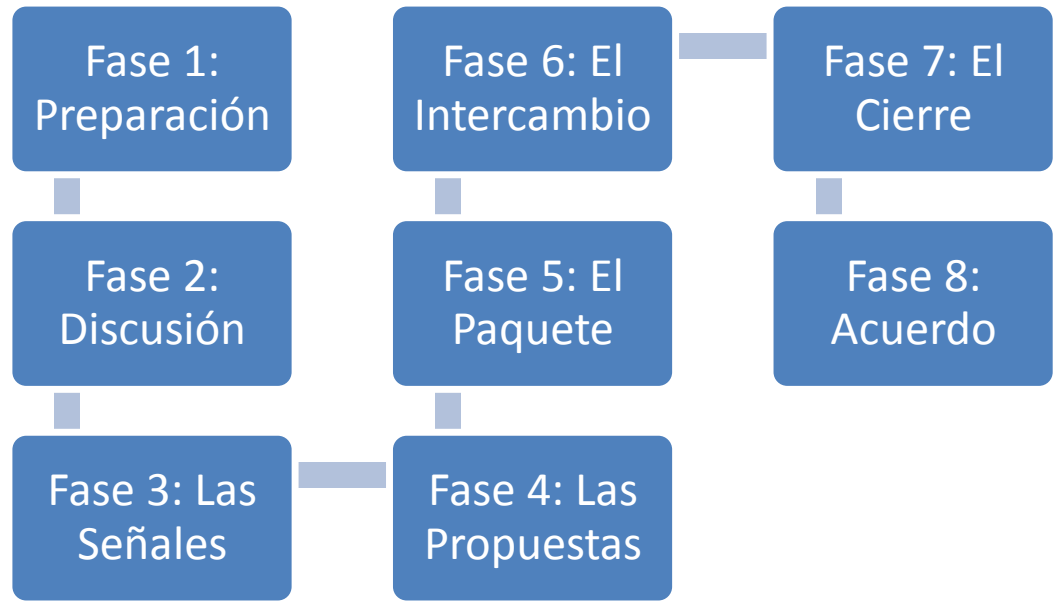

Fuente: Elaboración propia

\section{El cierre}

Similar a las fases previas, la negociación mantiene su terreno incierto (inestable, inseguro y movedizo). La finalidad del cierre es llegar a un acuerdo y el objetivo de este puede variar dependiendo del modelo; por ejemplo, si aplicamos el "ganar-ganar" se buscará un cierre que beneficie ambas partes. 
El cierre debe ser convincente (la veracidad) y para la aceptación del paquete, debe satisfacer bastantes necesidades de la otra parte; su propósito es conseguir un acuerdo sobre lo que se ofrece. Si hay un cierre sin éxito, se retorna, por lo general, a la fase de discusión y a otro ciclo de intercambio.

Entre las técnicas más comunes se tienen dos: el cierre con concesión y el cierre con resumen, según lo indica Kennedy y cols, (citado en Ovejero, p.129).

\section{$\underline{\text { 8. Acuerdo }}$}

Como última etapa de una negociación, aquí se materializa el esfuerzo del proceso previo. Las recomendaciones pertinentes de llegar a un acuerdo:

- Los negociadores deben leer y aprobar un resumen detallado de cada uno de los puntos negociados y si hay duda o no están de acuerdo en alguno, ha de buscarse la solución.

- Puede ser conveniente enviar a la otra parte una versión escrita del resumen inmediatamente después de la reunión. Se sugiere, inclusive, dejar claros los detalles menores en lo que respecta a la manera como se han de ejecutar los acuerdos, pues podría pasar mucho tiempo entre la toma del acuerdo y su implementación, así que es sano dejar formalizado los aspectos de forma.

- Finalmente, los intereses de las partes deben quedar sufragados y ambas partes deben estar de acuerdo con ello; se tiene que dejar constancia por escrito.

La base de la actividad de NEGOCIACIONES se fundamenta en el Construccionismo Social; "...la realidad aparece como una construcción humana que informa acerca de las relaciones entre los individuos y el contexto y el individuo aparece como un producto social..." (Serrano \& Pons, p.9).

Por otra parte se indica que "el proceso de comprensión es el resultado de una tarea cooperativa y activa entre personas que interactúan y el grado en que esa comprensión prevalece o es sostenida a través del tiempo está sujeto a las vicisitudes de los procesos sociales (comunicación, negociación, conflicto, etc.)" (p.9). Este tipo de procesos se observan en una actividad colaborativa como la que se estudia en este documento, ya que se dan 
interacciones entre los individuos para comunicarse entre ellos, así como el aspecto central que es realizar negociaciones y por supuesto también se presentan conflictos.

El concepto de comunidad de aprendizaje se define como "un grupo de personas que aprende en común, utilizando herramientas comunes en un mismo entorno." (p.10) Esto es casualmente a como están conformados los grupos para desarrollar la actividad de negociaciones.

\section{Metodología}

Tratando de simular la lógica de un proceso de negocios típico del área de compras que se da en las empresas, se buscó crear una actividad donde el estudiante tuviese un espacio para poner en práctica sus habilidades de negociador, además de poder construir de forma colaborativa su aprendizaje utilizando uno de los modelos de negociación que se utilizan en el área de compras.

En el anexo 1 se encuentra la descripción de las actividades en líneas que se han trabajado entre 2008 a 2014 para la asignatura 438. Ahí está explicada de manera general la actividad llamada NEGOCIACIONES, la cual se implementa a partir del 2010; siendo sobre esta que se desarrolla el tema central de la presente investigación y donde los estudiantes realizan su trabajo colaborativo para lograr desarrollarla.

La figura 2 representa el esquema de la actividad colaborativa "Negociaciones" para dar una idea general de cómo se estructura en la plataforma tecnológica, donde ha de quedar la evidencia de las interacciones y aporte de cada estudiante. El número de grupos se configura acorde con la matrícula total de estudiantes con la intención que aproximadamente 8-10 estudiantes por grupo; ha resultado en actividades con 8 a 10 grupos. 


\section{Figura 2: Esquema de la actividad colaborativa en la Plataforma Tecnológica (PT)}
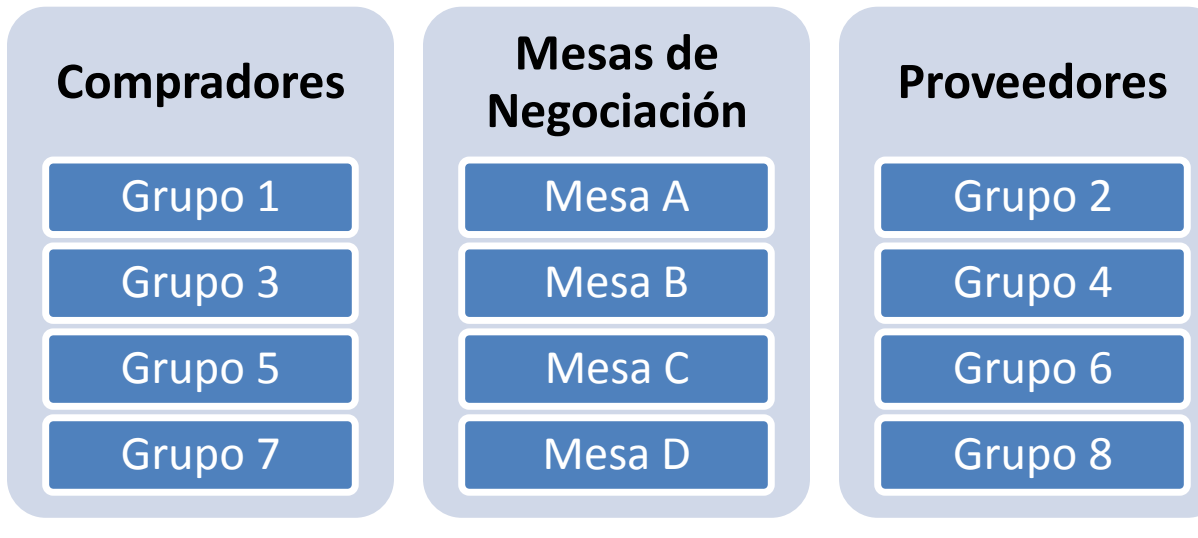

Fuente: Elaboración propia

Entonces, se trata de que los grupos conformados representen empresas, donde los estudiantes jugarán distintos roles según se organicen internamente. Puede observarse que hay una mesa de negociación por cada dos grupos, de tal forma que en cada mesa habrá personas haciendo roles de negociadores, por ejemplo, en la "Mesa A" negocian personas de los grupos 1 y 2; así sucesivamente para las otras mesas y grupos donde se encuentras integrados los estudiantes. La actividad tiene dos grandes etapas, según puede observarse en la figura 3:

a) La organización de las empresas participantes, donde lo primero es que cada estudiante se "auto-inscriba" en alguno de los grupos previstos en la plataforma para luego que termine el período de inscripción, procedan en cada grupo a organizarse en aspectos básicos (ejemplo, identificación de cada integrante, compartir información de contacto para comunicarse, como se van a coordinar, nombre de su empresa), luego deben ponerse de acuerdo para nombrar un representante de cada empresa (o equipo), quién tendrá el rol de negociador por esa empresa.

b) el ciclo de negociaciones entre representantes de empresas suele ser cíclico y se trata que en cada mesa de negociación "se siente" a negociar un representante por cada empresa (según lo indicado en figura 2), donde los estudiantes en su rol a jugar, buscarán el beneficio para sus empresas y lograr los objetivos requeridos en las instrucciones. 
La actividad continúa desarrollándose de manera muy dinámica a lo largo de 15 días que dura, así los estudiantes pueden tener el espacio para organizarse e ir cumpliendo con los requerimientos de que sigan el modelo de negociación de las ocho fases, esquematizado previamente en la figura 1, y además avanzando en obtener la información necesaria para buscar el beneficio de sus empresas.

Figura 3: Estructura del modelo de la actividad colaborativa

\section{a) Organización de las empresas}
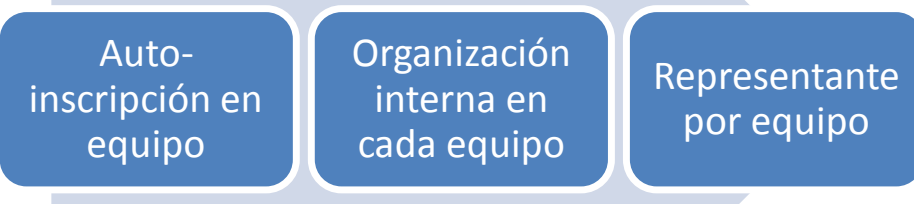

b) Ciclo de negociaciones entre representantes de empresas

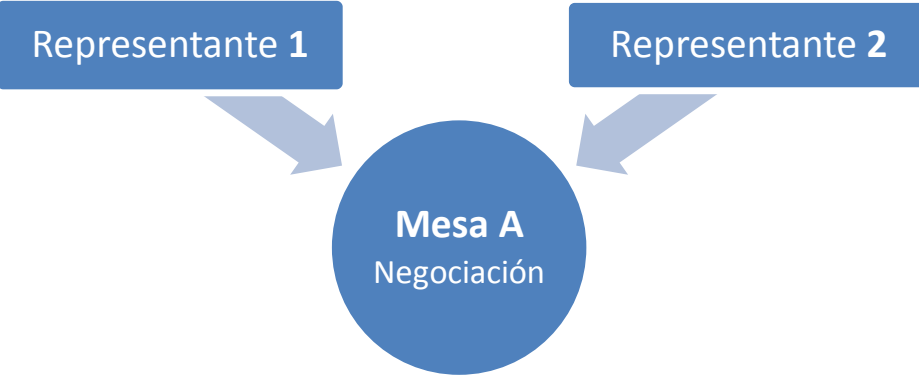

Fuente: Elaboración propia 
Si bien es cierto que en estos cinco años (2010-2014) de realizar la actividad de "NEGOCIACIONES", se han hecho ajustes en la dinámica desarrollada. No obstante, el modelo de interacciones han sido básicamente el mismo que se aprecia en figura 4, iniciando el ciclo con las instrucciones que van dadas en un horizonte de tiempo (ver anexo 2) para que los equipos cumplan en ese término. Luego se genera la dinámica dentro de los grupos, la cual queda evidenciada en la plataforma (ver anexo 3), ya que se le habilitan herramientas que la tecnología permite (blog, diario y foros) para ser utilizada por los estudiantes, a las cuales se da seguimiento por parte de tutores que atienden la plataforma.

Una vez organizado los equipos, proceden a ejecutar sus tareas, según lo que cada integrante acordó realizar en su fase previa. Vale aclarar la solicitud expresa hecha en las instrucciones acerca de utilizar información real, brindando evidencia de las fuentes de dónde se toma. Cada integrante aporta información o procesa lo que otro compañero aporta, de manera tal que trabaja sobre algún formato relacionado con la temática de la asignatura (RFI, RFQ, RFP², contratos, facturas y otros) según las instrucciones.

Posteriormente, a manera de cierre de un ciclo, los representantes ingresan a sus mesas respectivas de negociación y hacen el intercambio de información según el caso siguiendo lo establecido en instrucciones. De aquí pueden pasar de regreso a la dinámica interna de la empresa, donde discuten lo negociado y revisar la información que entregó el otro representante en la mesa de negociación.

\footnotetext{
${ }^{2}$ Siglas del ingles: RFI $\rightarrow$ Request for Information, RFQ $\rightarrow$ Request for Quotation, RFP $\rightarrow$ Request for Proposal
} 
Figura 4: Ciclo general de la actividad colaborativa

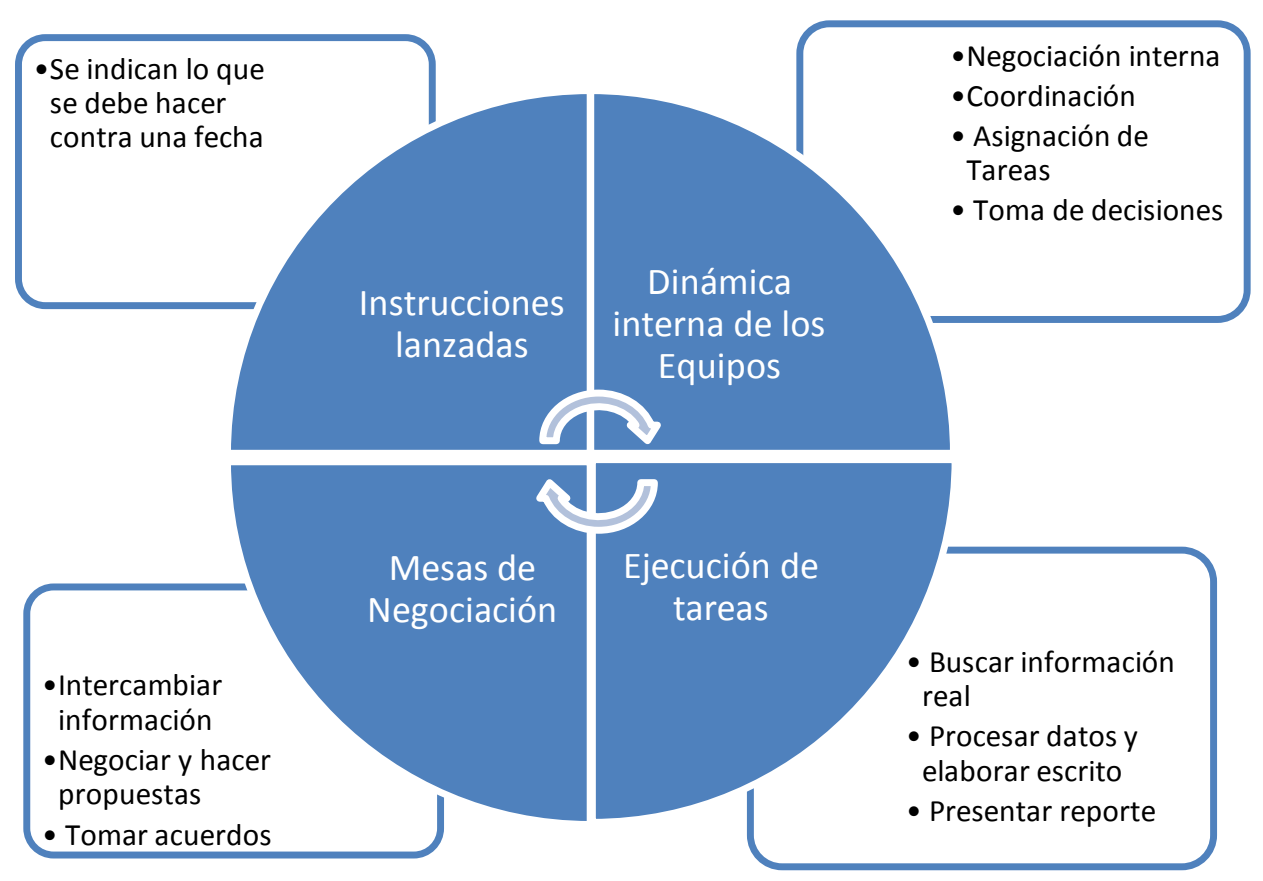

Fuente: Elaboración propia

Así sucesivamente y siguiendo lo establecido en instrucciones, continúa el ciclo de la actividad hasta llegar al cierre. A cada etapa de la actividad, los tutores dan seguimiento con una rúbrica (ejemplos en anexos 4 y 5 ) o herramienta para ir evaluando el rol desempeñado por cada estudiante y brindando la oportuna realimentación. La evaluación implica calificación tanto por los aportes individuales como los logros grupales; es decir, si el grupo alcanza desarrollar los requisitos de alguna etapa, todos los integrantes reciben la calificación; sin embargo, se puede evidenciar si algún miembro no contribuyó en nada y obtendría un cero.

\section{Logros alcanzados}

Los estudiantes llegan a identificarse con los roles que realizan dentro de la actividad. Ellos elaboran documentos acercándose a la realidad utilizando, tanto nombres reales de los artículos por negociar, como de los formatos empleados en el mundo empresarial, a como puede apreciarse en los ejemplos que se muestran en el anexo 6. 
Por otra parte, se observa la generación de una verdadera dinámica de colaboración que se va presentando a medida que avanza la actividad, dándose una honesta comunicación a lo interno de los grupos y también la coordinación que procuran realizar (ver ejemplo anexo 7), así como intercambio de archivos que en uno de los grupos se llegó a contabilizar más de 20 intercambios de archivos a lo largo del proceso de desarrollo de la actividad. Se observan estudiantes buscando coordinar para realizar las tareas de la manera más eficiente, a la vez que tratan de cumplir con dejar la evidencia solicitada para su propia evaluación y realimentación en su proceso de aprendizaje.

Los intercambios de información que se realizan dentro de las mesas de negociación, van siguiendo las instrucciones y puede encontrarse evidencia clara de esto (ver anexo 8) en las interacciones que hay entre los distintos pares que juegan el rol de representantes empresariales.

Al final de la actividad se espera que el estudiante alcance los siguientes objetivos, que viene a ser la evaluación del aprendizaje de dicha tarea, según se cita [Jirón, E; (2011) Descripción curricular de Compras y Almacenamientos. PACE, UNED]:

- Reconocer distintos estilos de negociación con proveedores.

- Determinar los modelos de negociación más convenientes a seguir para la gestión de compras según el caso.

- Utilizar los procedimientos para llevar a cabo una negociación que busca generar beneficios a su organización.

También, a como se evidencia, los estudiantes ponen en práctica sus habilidades de trabajar en equipo, su liderazgo, el compromiso para el alcance de objetivos; todo ello son competencias que el profesional de administración de empresas requiere haber desarrollado para forjar su desempeño exitoso. En esta actividad se logra brindar un entorno y retos suficientes para que utilicen este tipo de habilidades, lo cual se refleja en las evaluaciones individual y grupal que se hacen. 


\section{Análisis de la experiencia}

Mientras los estudiantes van construyendo su aprendizaje en el contexto de la actividad, donde ponen en práctica la teoría y además, en esa dinámica generada, sale a la luz las habilidades blandas de cada integrante, algunos demuestran rápidamente su liderazgo y suelen ser quiénes organizan al equipo dentro de cada empresa. Esto les brinda la oportunidad de interactuar con el entorno, como lo señalan los fundamentos del constructivismo social.

Por otra parte, entre más rápido se organizan los equipos, su eficiencia para asignarse tareas y obtener resultados puede apreciarse con la rápida entrega y cumplimiento con lo solicitado a realizar, donde también hay un proceso de toma de decisiones a lo interno de las "empresas" que se simulan. Muchos estudiantes tratan de encontrar maneras para comunicarse más expeditamente de lo que permite la plataforma, algunos mencionan utilizar herramientas que la tecnología actual les permite como Skype, Google docs. y otras. Esto evidencia la preocupación por el cómo realizar esa construcción del aprendizaje, lo cual tratan de resolver a lo interno de los grupos.

Hay una alta demanda de atención por los estudiantes a la actividad, en los intercambios de archivos puede observarse esto, así como en la coordinación que se percibe a lo interno de los grupos. Esto muestra el compromiso que asumen cuando se les plantea retos en su aprendizaje y en cierta manera se les facilita un contexto que les permite encontrarle sentido de aplicar directamente a una situación semejante a la vida real, sus conocimientos aprendidos.

En la dinámica de los grupos se puede observar la cohesión y en algunos casos, se genera un ambiente de camaradería y solidaridad que algún miembro del equipo abiertamente expresa no comprender algo, solicitando aclaración al respecto. Esto va construyendo un aprendizaje social, donde se puede decir hay una pequeña "comunidad de aprendizaje"(Serrano, p.10); en el interior de cada grupo de trabajo, ya que se tiene la presencia de un proceso de comprensión resultante de una tarea cooperativa y activa entre los estudiantes que se comunican, negocian y se observa que también tienen sus conflictos en algunos momentos.

La evaluación que se les va brindando a lo largo de la actividad, les insta a mejorar a medida que se avanza en el ciclo de negociaciones. En los primeros dos años que se realizó la 
actividad, se aplicaba una rúbrica al final de la actividad y solamente servía para que el estudiante se enterara donde había fallado; sin embargo, cuando se comenzó a realizar evaluación a lo largo de la actividad, la reacción de los estudiantes fue de mostrar más interés en las etapas que tenía por delante. Lo anterior, a como lo indica Alvarez, (citado en Jarauta, 2012, p.142) "Y al cambiar las formas de evaluar cambiarán asimismo las formas en las que los alumnos aprenden, porque previamente habrán cambiado las formas de enseñar"; enseña que el aprendiz está a la expectativa de cómo va realizando la aplicación de lo aprendido y se puede percibir un cierto stress por la incertidumbre sobre su desempeño".

En la actividad del 2014 se estableció temas por grupos (Mercadeo, Salud, Banca y otros) que ayudó para que estudiantes provenientes de carreras relacionadas con estos temas, se identificaran más con la actividad, además que inscribían en las de su afinidad con mayor probabilidad de encontrar otros pares de la misma carrera o bien con intereses similares.

\section{Lecciones aprendidas}

- La evaluación continua le despierta al estudiante un reto permanente durante su proceso de aprendizaje y se preocupa por aprender significativamente para alcanzar su propia superación.

- El trabajo colaborativo motiva al estudiante en el proceso de aprendizaje y se solidariza con las metas comunes que tienen como equipo.

- La realimentación oportuna le brinda oportunidad de aprender donde falló o también que va por buen camino en su proceso de aprender.

- Buscar la adaptación de la actividad colaborativa para que sea aplicable con otras tecnologías más flexibles para el estudiante y a la vez que permitan dejar la evidencia necesaria para poder evaluar el aporte individual en la construcción del conocimiento colaborativamente.

- La importancia de facilitar a los estudiantes este tipo de actividades colaborativas, aunque sea por medio de las PT, ya que les permite enriquecer sus conocimientos con la perspectiva de otros adicional a la propia que cada uno pueda tener.

- La claridad de las instrucciones para este tipo de actividades, le facilita al estudiante su realización y pronto inicio del desarrollo de las tareas requeridas. 
- Al analizar y revisar el proceso general de esta actividad, se rescata la importancia de contar con medios para desarrollar este tipo de prácticas colaborativas entre pares para el estudiante de administración de empresas.

- La construcción social del conocimiento en un sistema a distancia, debe ser un componente que esté presente en los modelos de evaluación de diversas asignaturas de una carrera, ya que ayuda al estudiante a poner en práctica ese conjunto de habilidades que de otra forma no las pondría a prueba.

- Este tipo de actividades podría buscar cómo dirigirse para conseguir resultados concretos en la generación de soluciones a problemas o retos que se les plantee a los estudiantes, manejando el concepto de "comunidades de aprendizaje"

- El fomentar que los estudiantes apliquen conocimientos teóricos y además que los pongan en práctica, resulta que hacen uso de ciertas habilidades (por ej., trabajo en equipo, liderazgo, saber escuchar, aprender a tolerar y otras) utilizadas para el éxito en el mundo profesional y forjan de alguna manera sus competencias gerenciales.

\section{Referencias}

Universidad Estatal a Distancia. Cátedra de Producción (2014). Orientaciones académicas para la asignatura Compras y Almacenamientos - 3er cuatrimestre.

Universidad Estatal a Distancia. Cátedra de Producción (2014). Orientaciones académicas para la asignatura Compras y Almacenamientos - 2do cuatrimestre.

Universidad Estatal a Distancia. Cátedra de Producción (2013). Orientaciones académicas para la asignatura Compras y Almacenamientos - 3er cuatrimestre.

Universidad Estatal a Distancia. Cátedra de Producción (2012). Orientaciones académicas para la asignatura Compras y Almacenamientos - 3er cuatrimestre.

Universidad Estatal a Distancia. Cátedra de Producción (2011). Orientaciones académicas para la asignatura Compras y Almacenamientos - 3er cuatrimestre.

Universidad Estatal a Distancia. Cátedra de Producción (2010). Orientaciones académicas para la asignatura Compras y Almacenamientos - 3er cuatrimestre.

Universidad Estatal a Distancia. Cátedra de Producción (2009). Orientaciones académicas para la asignatura Compras y Almacenamientos - 3er cuatrimestre.

Universidad Estatal a Distancia. Cátedra de Producción (2008). Orientaciones académicas para la asignatura Compras y Almacenamientos - 3er cuatrimestre. 
Jarauta, B. \& Imbernón, F. (Coord.) (2012). Pensando en el futuro de la educación; una nueva escuela para el siglo XXII. 139-158.

Jirón, E. (2011). Descripción curricular de Compras y Almacenamientos. Programa de Apoyo Curricular y Evaluación de los Aprendizajes. (PACE), UNED

Lloyd, P. (1994). GroupWare in the 21st Century: Computer Supported Cooperative Working toward the Millennium. Greenwood Publishing Group Inc. Westport, CT, USA (C1994

Lucero, M. M. (2003). Entre el trabajo colaborativo y el aprendizaje colaborativo. Revista Ibero Americana de Educación. Recuperado de http://www.fvet.uba.ar/postgrado/especialidad/aprendizajecolaborativo.pdf

Martín, A.M., Domínguez, M. \& Paralera, C. (2011). El entorno virtual: un espacio para el aprendizaje colaborativo. (Edutec) Revista Electrónica de Tecnología Educativa, 35, 1-9.

Ovejero, A. (2004). Técnicas de Negociación: Cómo negociar eficaz y exitosamente. Madrid: Mc-Graw-Hill.

Programa de Apoyo Curricular y Evaluación de los Aprendizajes (PACE). (2014). Glosario de Términos Curriculares para UNED. Programa de Producción de Material Didáctico Escrito, (PROMADE), UNED. Recuperado de: http://www.uned.ac.cr/academica/images/PACE/publicaciones/FINAL24-913 Glosario de trminos curriculares UNED.pdf

Serrano, J. M. y Pons, R. M. (2011). El constructivismo hoy: enfoques constructivistas en educación. Revista Electrónica de Investigación Educativa, 13(1), 6-9. Recuperado de http://redie.uabc.mx/vol13no1/contenido-serranopons.html

Vega, C. (2005). Integración de herramientas de tecnologías de información "portales colaborativos de trabajo" como soporte en la administración del conocimiento. Tesis de doctorado. Universidad Popular Autónoma del Estado de Puebla, Puebla, México. Recuperado de http:// http://catedragc.mes.edu.cu/download/Tesis\%20de\%20Doctorado/Ingeniera\%20Industrial \%20-\%20Internacionales/CarlosArturoVegaLebr\%C3\%BAn.pdf 


\section{ANEXO 1 \\ DESCRIPCIÓN DE ASIGNACIONES ${ }^{3}$}

\section{AÑO 2008:}

Los estudiantes deberán realizar, según opción escogida ( $A \circ B$ ) una tarea y un trabajo de campo, adicional (en caso B) la participación en 4 foros:

7.1 TAREA UNICA (Ver fecha de presentación en punto I)

1. Seleccionar una organización (de manufactura o elaboración de productos), describir su actividad comercial, tipo de empresa, los productos elaborados y su posición competitiva en el mercado (regional, nacional, internacional).

Nota: si la organización es de servicios debe contar con la APROBACIÓN PREVIA DEL TUTOR o LA CATEDRA (Ver punto VIII)

2. Aplicar la norma CIAMO (del archivo 438_Ciamo.doc) o el CheckList Oliver Wight (si fuese el instrumento subido a WEBCT) a la empresa, determinar qué puntos aplican y cuáles NO aplican. Para los puntos que aplican NO debe determinarse el porcentaje de aplicación (NO calificar).

3. Resuma y comente los indicadores de Administración de materiales que utiliza la empresa para controlar: recibo, custodia, entrega y niveles de servicio de los inventarios. También comente la forma de controlar las existencias o inventarios.

NOTA: La tarea se puede realizar individual o en grupo (máx. 4 integrantes)

\section{AÑO 2009:}

Los estudiantes deberán realizar, según opción escogida $(A \circ B)$ una tarea de investigación aplicada y un trabajo de campo, o bien (en caso B) la participación en 2 foros virtuales (en WEBCT) relacionados a temas que tendrán que investigar y aplicarlos en actividades que se realizarán con apoyo por medio de los foros:

\subsection{TAREA de Investigación (Fecha de entrega en Cronograma) (Opción "A")}

1. Seleccionar uno de los temas que están en WEBCT, en la sección de "asignaciones" (encontrará dos alternativas) y realizar la investigación suficiente para que pueda elaborar un marco teórico sustancioso que le servirá de referencia en el resto de la tarea.

2. Elija un producto de consumo masivo (ej. pasta de dientes, jabones, galletas, gaseosas, pan, chicles, cervezas, shampoo, desodorante, etc.) o alguno de uso industrial (ej. Harina, azúcar,

\footnotetext{
${ }^{3}$ El contenido de toda esta información es extraído del documento Orientaciones de la asignatura Compras y Almacenamiento (cód. 438); y según el año que se indica en negrillas en este anexo.
} 
cajas de cartón, material de empaque, etc.). Debe indicar la marca y presentación que está eligiendo de dicho producto y tome 3 materias primas o ingredientes que componen dicho producto e investigue:

- Al menos un suplidor (local o internacional) que venda c/u de estas materias primas y dónde está ubicado (coordenadas exactas).

- Precio real por kilo (o por presentación) indicando la fuente (si lo tomó de Internet_link, una revista_bibliografía, factura _ adjunte fotocopia, etc.)

- Comente cuáles serán los elementos claves a considerar, basado en los temas escogidos para su propia investigación (pto. 1), si Usted fuera el comprador de dichos 3 ingredientes que va a negociar con c/u de los suplidores.

- Si Usted fuese el proveedor que vende c/u de estas materias primas qué aspectos claves ofrecería de cara al futuro para asegurarse la lealtad de su cliente.

3. Dado que el producto lo puede adquirir en diversos establecimientos (ej. un supermercado, pulpería, bodegón, fábrica, etc.), puede elegir el lugar dónde lo compró o el canal (_ concepto marketing) dónde se suele distribuir. Investigue (observando o preguntando) cómo es entregado dicho producto en ese mismo sitio y describa:

- Nombre de empresa que lo distribuye en ese canal (indique el tipo de canal_ refiera el libro de mercadeo u otro donde encontró la clasificación del tipo de canal).

- Embalaje (tarima, cajas cartón $x$ tarima, unidades $x$ caja)

- Frecuencia de entrega (ej. 2xsemana, 3xmes, etc.) de dicho artículo (producto y presentación elegida) que hace el proveedor al establecimiento donde Usted lo adquirió.

- Como dueño del establecimiento, cuáles consideraciones hay que tomar en cuenta basado en la investigación (pto. 1) para esta parte.

- De ser Usted el distribuidor que abastece al establecimiento, ¿qué le ofrecería al cliente (dueño o administrador) para mejorar el servicio?

4. Comente cuáles indicadores (al menos 3) de Administración de materiales recomendaría que utilice la empresa (fabricante del producto) para controlar en las materias primas (m.p.): recibo, custodia, entrega y niveles de servicio de los inventarios. Justifique porqué eligió dichos indicadores.

5. También comente la forma de controlar las existencias o inventarios en general para el fabricante del producto que adquirió. 


\section{NOTA: El formato de presentación de Tarea estará en WebCT para su ilustración.}

Los estudiantes deberán realizar 2 actividades en línea (en BLACKBOARD LEARN) y un trabajo de campo.

Tanto la "Investigación" como este "Trabajo de campo" se puede realizar en grupo (máximo cuatro personas) o de forma individual.

\section{AÑO 2010:}

\subsection{Actividades en línea:}

\subsubsection{Investigación (Ver en Cronograma, Actividad en Línea 1)}

1. Elija un producto de consumo masivo (ej. pasta de dientes, jabones, galletas, gaseosas, pan, chicles, cervezas, shampoo, desodorante, etc.) o alguno de uso industrial (ej. Harina, azúcar, cajas de cartón, material de empaque, etc.). Debe indicar la marca y presentación que está eligiendo de dicho producto y tome 3 materias primas o ingredientes que componen dicho producto e investigue:

- Al menos un suplidor (local o internacional) que venda c/u de estas materias primas y dónde está ubicado (coordenadas exactas).

- Precio real por kilo (o por presentación) indicando la fuente (si lo tomo de Internet $\rightarrow$ link, una revista $\rightarrow$ bibliografía, factura $\rightarrow$ adjunte fotocopia, etc.)

- Comente cuáles serán los elementos claves a considerar, basado en los conceptos del Material Complementario 1, si Usted fuera el comprador de dichos 3 ingredientes que va a negociar con c/u de los suplidores.

- Si Usted fuese el proveedor que vende c/u de estas materias primas que aspectos claves ofrecería de cara a futuro para asegurarse la lealtad de su cliente.

2. Dado que el producto lo puede adquirir en diversos establecimientos (ej. un supermercado, pulpería, bodegón, fábrica, etc.), puede elegir el lugar donde lo compró o el canal $(\rightarrow$ concepto marketing) donde se suele distribuir. Investigue (observando o preguntando) cómo es entregado dicho producto en ese mismo sitio y describa:

- Nombre de empresa que lo distribuye en ese canal (indique el tipo de canal $\rightarrow$ refiera el libro de mercadeo u otro donde encontró la clasificación del tipo de canal).

- Embalaje (tarima, cajas cartón $x$ tarima, unidades $x$ caja) 
- Frecuencia de entrega (ej. 2xsemana, 3xmes, etc.) de dicho artículo (producto y presentación elegida) que hace el proveedor al establecimiento donde Usted lo adquirió.

- Como dueño del establecimiento, cuáles consideraciones hay que tomar en cuenta basado en la investigación (pto. 1) para esta parte.

- De ser Usted el distribuidor que abastece al establecimiento, ¿qué le ofrecería al cliente (dueño o administrador) para mejorar el servicio?

3. Comente cuáles indicadores (al menos 3) de Administración de materiales recomendaría que utilice la empresa (fabricante del producto) para controlar en las materias primas (m.p.): recibo, custodia, entrega y niveles de servicio de los inventarios. Justifique porqué eligió dichos indicadores.

4. También comente la forma de controlar las existencias o inventarios en general para el fabricante del producto que adquirió.

\subsubsection{Negociaciones (Ver en Cronograma, Actividad en Línea 2)}

1. Con todos los estudiantes activos, se conformarán 8 equipos definidos por los tutores y en cada equipo se deberán de poner de acuerdo para nombrar 1 representante que irá a negociar los acuerdos internos de cada equipo.

2. Los equipos serán listados en la plataforma para que cada miembro conozca donde está y quiénes son los demás compañeros.

3. Se construirán 8 cuartos virtuales donde solamente podrán ingresar los integrantes de cada equipo.

4. Habrá un cuarto virtual de negociaciones, donde solamente tendrán acceso los representantes previamente elegidos. En este cuarto se llevarán a cabo las negociaciones entre los representantes y donde ejecutarán los acuerdos que llevan de sus equipos, a la vez deberán tomar decisiones en el momento para concretar negocios con los demás representantes.

5. Las indicaciones de las negociaciones serán subidas a la plataforma, sección de "actividades" después de la segunda tutoría, así como las reglas que rigen estas actividades.

6. La nota obtenida para esta actividad irá en función del alcance y logro de los objetivos establecidos para dicha actividad (ver punto 5) por cada equipo y los cuáles serán aplicados a los 8 miembros por igual. 
NOTA: El formato de presentación de Investigación estará en sección de "Materiales" BlackboardLearn para su ilustración.

Tanto la "Investigación" como este "Trabajo de campo" se puede realizar en grupo (máximo cuatro personas) o de forma individual.

\section{AÑO 2011:}

Los estudiantes deberán realizar 2 actividades en línea (en BLACKBOARD LEARN) y un trabajo de campo. Todas las asignaciones se realizan en grupo, los detalles se dan según cada caso, no obstante, la conformación la realiza el estudiante con sus pares en acuerdo mutuo sin intervención de tutores.

La presentación de reportes de trabajo sigue el formato: Arial 12 y espacio interlínea de 1.5.

\subsection{Actividades en línea:}

4.2.1 Investigación (Ver en Cronograma, Actividad en Línea 1): se puede realizar en grupos (máximo 3 integrantes), la extensión no debe exceder de 10 páginas. Tiene dos grandes temas a investigar, manteniendo la perspectiva del área de compras, sobre los puntos enunciados:

1. Costos y Presupuestos

a. Teoría de los costos

i. ¿Qué es la contabilidad de costos? ¿Cómo agrupa los costos?

ii. ¿Qué son los costos? ¿Qué son los gastos?

iii. ¿Qué función cumplen los costos en la empresa?

iv. ¿Cuáles factores intervienen en los costos?

v. ¿Métodos de costeo en las empresas?

b. Teoría del TOC (Teoría de las restricciones)

i. Qué es el TOC? Enumere y describa los conceptos básicos del TOC.

ii. Cómo se puede identificar la aplicabilidad del TOC?

iii. Defina y explique los 3 medidores de desempeño del TOC.

iv. Cuáles son los principios básicos del TOC?

c. Presupuestos

i. ¿Cuáles son las funciones y objetivos de los presupuestos?

ii. ¿Qué es el calendario presupuestal?

iii. ¿Cómo se clasifican los presupuestos? 
d. Ejercicios prácticos donde aplique el aspecto de costos y presupuestos a las funciones de compras.

i. Busque dos ejercicios donde aplique dos de los tres tópicos arriba descritos (1, 2 ó 3) al área de compras.

ii. Desarrolle un ejemplo de su propia creación, donde utilice la teoría de esta investigación (tópico sin ejercicio del punto i), como parte de un ejercicio práctico en que se aplique a la temática de los procesos de compras.

2. Plataformas Tecnológicas de Apoyo a la Gestión de Compras

a. Definición y usos

i. ¿Qué es una plataforma tecnológica? ¿Ventajas de invertir en ella?

ii. ¿Para qué se utilizan las plataformas tecnológicas en la gestión de compras?

iii. Liste siete aspectos donde dichas plataformas ayudan a mejorar procesos de compras.

b. Clasificación de las plataformas tecnológicas (P.T.)

i. Indague sobre tres P.T. específicas o particulares (SAP, ORACLE, LINUX, MACOLA, BPCS, SIIGO, SICOF u otras), describa en 2-3 párrafos sobre lo que c/u hace en los procesos de compras y además mencione 4 ventajas que ofrece c/u en lo que la temática de compras se refiere.

ii. Investigue cuáles son las P.T. del estado aplicado a la gestión de compras. ¿Cómo se regula y controla la definición de P.T. del estado costarricense?

c. Intercambio electrónico de datos y/o documentos (EDI) aplicados a la gestión de compras

i. Describa qué es el EDI, elabore un esquema explicativo que resuma las interacciones. ¿Quién regula el EDI en Costa Rica?

ii. Cite y explique los componentes básicos del EDI.

iii. ¿Cómo funciona el EDI (Muestre un esquema)?

d. Aplicación del EDI a la gestión de compras.

i. En qué procesos o actividades de la gestión de compras se puede aplicar EDI?

ii. Enumere 10 ventajas del EDI para la gestión de compras.

iii. Describa dos escenarios donde se muestre la aplicación del EDI.

CONCLUSIONES: En media página exponga las conclusiones a que le lleva la presente investigación, es decir, lo que aprendió y lo que le gustaría investigar más sobre los temas. 
Además, debe responder a la pregunta de cuál temática considera más útil para su formación y porqué.

4.2.2 Negociaciones (Ver en Cronograma, Actividad en Línea 2): Para realizar esta actividad se requiere hacer uso de la P.A.L. (BbLearn) y su coordinación con otros compañeros para incorporare en cada grupo de trabajo se hace por medio de dicha plataforma.

1. Con todos los estudiantes activos, se conformarán 8 equipos definidos por los tutores y en cada equipo se deberán de poner de acuerdo para nombrar 1 representante que irá a negociar los acuerdos internos de cada equipo.

2. Los equipos serán listados en la plataforma para que cada miembro conozca donde está y quiénes son los demás compañeros.

3. Se construirán 8 cuartos virtuales donde solamente podrán ingresar los integrantes de cada equipo.

4. Habrá un cuarto virtual de negociaciones, donde solamente tendrán acceso los representantes previamente elegidos. En este cuarto se llevarán a cabo las negociaciones entre los representantes y donde ejecutarán los acuerdos que llevan de sus equipos, a la vez deberán tomar decisiones en el momento para concretar negocios con los demás representantes.

5. Las indicaciones de las negociaciones serán subidas a la plataforma, sección de "actividades" después de la segunda tutoría, así como las reglas que rigen estas actividades.

6. La nota obtenida para esta actividad irá en función del alcance y logro de los objetivos establecidos para dicha actividad (ver punto 5) por cada equipo y los cuáles serán aplicados a los 8 miembros por igual.

NOTA: La estructura de presentación de Investigación estará en sección de "Materiales" BlackboardLearn para su ilustración.

\section{AÑO 2012:}

Los estudiantes deberán realizar 2 actividades en línea (en BLACKBOARD LEARN) y un trabajo de campo. Todas las asignaciones se realizan en grupo, los detalles se dan según cada caso, no obstante, la conformación la realiza el estudiante con sus pares en acuerdo mutuo sin intervención de tutores.

La presentación de reportes de trabajo sigue el formato: Arial 12 y espacio interlínea de 1.5. 


\subsection{Actividades en línea:}

4.1.1 Investigación (Ver en Cronograma, Actividad en Línea 1): se puede realizar en grupos (máximo 3 integrantes), la extensión no debe exceder de 10 páginas. Tiene dos grandes útiles temas a investigar (se hacen los dos),manteniendo la perspectiva del área de compras, sobre los puntos enunciados:

1. Costos y Presupuestos

a. Teoría de los costos

i. ¿Qué son los costos? ¿Qué son los gastos?

ii. ¿Qué función cumplen los costos en la empresa?

iii. ¿Cuáles factores intervienen en los costos?

iv. Importancia de la relación Costo/Precio y cómo los proveedores establecen el precio.

b. Presupuestos

i. ¿Cuáles son las funciones y objetivos de los presupuestos?

ii. ¿Qué es el calendario presupuestal?

iii. ¿Cómo se clasifican los presupuestos?

iv. ¿Cuáles son las fuentes de información relacionadas con las tendencias en precios? (refiérase al sector empresarial donde realiza el proyecto)

c. Ejercicios prácticos donde aplique el aspecto de costos y presupuestos a las funciones de compras.

i. Busque o desarrolle dos ejercicios donde aplique c/u de los dos tópicos arriba descritos al área de comprasen la empresa donde elabora el proyecto. (en cualquier caso indique la referencia bibliográfica o si son de su creación "fuente propia")

2. Plataformas Tecnológicas de Apoyo a la Gestión de Compras

a. Definición y usos

i. ¿Qué es una plataforma tecnológica? ¿Ventajas de invertir en ella?

ii. ¿Para qué se utilizan las plataformas tecnológicas en la gestión de compras?

iii. Liste siete aspectos donde dichas plataformas ayudan a mejorar procesos de compras.

b. Clasificación de las plataformas tecnológicas (P.T.)

i. Indague sobre tres P.T. específicas o particulares (SAP, ORACLE, LINUX, MACOLA, BPCS, SIIGO, SICOF u otras), describa en 2-3 párrafos sobre lo que c/u hace en los procesos de compras y además mencione 4 ventajas que ofrece c/u en lo que la temática de compras se refiere en la empresa donde está realizando su proyecto. 
ii. Investigue cuáles son las P.T. del Estado aplicadas a la gestión de compras en C.R. ¿Cómo se regula y controla la definición de P.T. del estado costarricense? Indique los sitios en internet donde se accedan algunas de estas.

c. Intercambio electrónico de datos y/o documentos (EDI) aplicados a la gestión de compras y almacenes.

i. Describa qué es el EDI, elabore un esquema explicativo que resuma las interacciones y cómo funciona.

ii. Cite y explique los componentes básicos del EDI.

iii. ¿Qué es el RFID y cómo funciona? (Muestre un esquema de sus aplicaciones para un almacén)

d. Aplicación del EDI y RFID a la gestión de compras y almacenes.

i. En qué procesos o actividades de la gestión de compras se puede aplicar EDI? Cite ejemplos (hipotéticos o reales) con referencia a la empresa donde realiza el proyecto.

ii. Enumere 5 ventajas del EDI y 5 del RFID que podría traer (o que tiene en caso que usen alguno) para la gestión de compras y almacenes donde realiza el proyecto.

e. Sistemas de adquisiciones electrónicas

i. ¿Qué son los sistemas de adquisiciones electrónicas y cuáles ventajas brinda?

ii. ¿Qué son catálogos en línea? Brinde 5 ejemplos que encuentre en internet (brinde la referencia respectiva)

iii. Si en la empresa donde realiza el proyecto, utilizaran sistema de adquisiciones electrónicas (o si lo utilizan), ¿cuáles serían las principales ventajas? ¿A quiénes debería capacitar para poder implementar su uso?

CONCLUSIONES: En media página exponga las conclusiones a que le lleva la presente investigación, es decir, lo que aprendió y lo que le gustaría investigar más sobre los temas. Además, debe responder a la pregunta de cuál temática considera más útil para su formación y porqué.

NOTA: La estructura de presentación de Investigación estará en sección de "Materiales" BlackboardLearn para su ilustración.

4.1.2 Negociaciones (Ver en Cronograma, Actividad en Línea 2): Para realizar esta actividad se requiere hacer uso de la P.A.L. (BbLearn) y su coordinación con otros compañeros para incorporarse en cada grupo de trabajo se hace por medio de dicha plataforma. 
1. Con todos los estudiantes activos, se conformará determinado número de equipos definidos por los tutores y en cada equipo se deberán de poner de acuerdo para nombrar 1 representante que irá a negociar los acuerdos internos de cada equipo.

2. Los equipos serán listados en la plataforma para que cada miembro conozca donde está y quiénes son los demás compañeros.

3. Se construirán cuartos virtuales de reunión donde solamente podrán ingresar los integrantes de cada equipo (simulando empresas) Aquí deben realizarse todas las coordinaciones internas de cada equipo; es la evidencia para evaluar a cada uno.

4. Habrá un cuarto virtual de negociaciones, donde solamente tendrán acceso los representantes previamente elegidos. En este cuarto se llevarán a cabo las negociaciones entre los representantes y donde ejecutarán los acuerdos que llevan de sus equipos, a la vez deberán tomar decisiones en el momento para concretar negocios con los demás representantes.

5. Las indicaciones de las negociaciones serán subidas a la plataforma, sección de "actividades" después de la segunda tutoría, así como las reglas que rigen estas actividades.

6. La nota obtenida para esta actividad irá en función del alcance y logro de los objetivos establecidos para dicha actividad (ver punto 5) por cada equipo y los cuáles serán aplicados a los miembros en dependencia del aporte y colaboraciones evidenciadas.

\section{AÑO 2013:}

Los estudiantes deberán realizar 2 actividades en línea (en BLACKBOARD LEARN) y un trabajo de campo. Todas las asignaciones se realizan en grupo, los detalles se dan según cada caso, no obstante, la conformación la realiza el estudiante con sus pares en acuerdo mutuo sin intervención de tutores.

La presentación de reportes de trabajo sigue el formato: Arial 12 y espacio interlínea de 1.5 .

\subsection{Actividades en línea:}

4.1.1 Investigación (Ver en Cronograma, Actividad en Línea 1): se puede realizar en grupos (máximo 3 integrantes), la extensión no debe exceder de 10 páginas. Tiene dos grandes útiles temas a investigar, manteniendo la perspectiva del área de compras, sobre los puntos enunciados: 


\section{Outsourcing}

a. ¿Qué es el outsourcing?

b. ¿Cuáles actividades podrían gestionarse bajo el esquema de outsourcing?

c. Diga las condiciones bajo las cuales podría implementar outsourcing.

d. Indique que ventajas y desventajas del outsourcing le traería a la empresa donde realiza el proyecto. (Cite al menos 5 ventajas y unas 2 desventajas.)

e. Representantes en planta

i. ¿A qué se refiere el término "representante en planta", cuáles son sus funciones y posibles objetivos?

ii. ¿Cuáles son las alternativas de operar bajo este esquema con "representante en planta"?

iii. ¿Qué ventajas obtiene el proveedor? ¿Qué ventajas obtiene el cliente?

f. Implicación temprana de Proveedores -Early Supplier Involvement (ESI).

i. Explicar a qué se refiere este modelo y mencione 2 ejemplos del tipo de industria donde se puede aplicar.

ii. Liste los principales factores a considerar para poder adoptar el modelo ESI.

iii. ¿Cuáles son las fases para gestionar el ESI?

CONCLUSIONES: En media página exponga las conclusiones a que le lleva la presente investigación, es decir, lo que aprendió y lo que le gustaría investigar más sobre los temas. Además, debe responder a la pregunta de cuál temática considera más útil para su proyecto y porqué.

4.1.2 Negociaciones (Ver en Cronograma, Actividad en Línea 2): Para realizar esta actividad se requiere hacer uso de la P.A.L. (BbLearn) y su coordinación con otros compañeros para incorporare en cada grupo de trabajo se hace por medio de dicha plataforma.

1. Con todos los estudiantes activos, se conformará determinado número de equipos definidos por los tutores y en cada equipo se deberán de poner de acuerdo para nombrar 1 representante que irá a negociar los acuerdos internos de cada equipo.

2. Los equipos serán listados en la plataforma para que cada miembro conozca donde está y quiénes son los demás compañeros.

3. Se construirán cuartos virtuales de reunión donde solamente podrán ingresar los integrantes de cada equipo (simulando empresas).

4. Habrá un cuarto virtual de negociaciones, donde solamente tendrán acceso los representantes previamente elegidos. En este cuarto se llevarán a cabo las negociaciones 
entre los representantes y donde ejecutarán los acuerdos que llevan de sus equipos, a la vez deberán tomar decisiones en el momento para concretar negocios con los demás representantes.

5. Las indicaciones de las negociaciones serán subidas a la plataforma, sección de "actividades" después de la segunda tutoría, así como las reglas que rigen estas actividades.

6. La nota obtenida para esta actividad irá en función del alcance y logro de los objetivos establecidos para dicha actividad (ver punto 5) por cada equipo y los cuáles serán aplicados a los miembros por igual.

\section{AÑO 2014 (2do cuatrim.):}

Los estudiantes deberán realizar 2 actividades en línea (en BLACKBOARD LEARN) y un trabajo de campo. Todas las asignaciones se realizan en grupo, los detalles se dan según cada caso, no obstante, la conformación la realiza el estudiante con sus pares en acuerdo mutuo sin intervención de tutores.

La presentación de reportes de trabajo sigue el formato: Arial 12 y espacio interlínea de 1.5 .

\section{Actividades en línea:}

i. Investigación (Ver en Cronograma, Actividad en Línea 1): se puede realizar en grupos (máximo 3 integrantes, mínimo 2 integrantes) la extensión no debe exceder de 10 páginas. Ésta actividad se envía al profesor a través de la plataforma en el link asignado en el "área de actividades". El link abre y cierra según fechas del cronograma de actividades. Tiene que investigar, manteniendo la perspectiva del área de compras, sobre los puntos enunciados:

2. Investigue sobre empresas de Servicios, industriales o agrícolas.

Valor Total $7,5 \%$

Tema 1: Empresas de servicios. Valor 3.75\%

a. ¿Cuáles características son propias de las empresas de servicios?

b. Investigue sobre una empresa de servicios y sintetice en qué consiste el sistema de abastecimiento de materiales de la empresa investigada. 
c. Elabore un diagrama del sistema de gestión de compras de la empresa de servicios investigada.

d. Cite el nombre de al menos una empresa de servicios de su comunidad, los servicios que aporta, y principales proveedores.

Tema 2: Empresas industriales o agrícolas. Valor 3.75\%

e. ¿Cuáles características son propias de la empresa qué elige?

f. Investigue sobre una empresa industrial o agrícola y sintetice en qué consiste el sistema de abastecimiento de materiales de la empresa investigada.

g. Elabore un diagrama del sistema de gestión de compras de la empresa investigada.

h. Cite el nombre de al menos una empresa industrial o agrícola de su comunidad, los productos que ofrece y principales proveedores.

CONCLUSIONES: En media página exponga las conclusiones a que le lleva la presente investigación, es decir, lo que aprendió y lo que le gustaría investigar más sobre los temas de gestión de compras.

ii. Negociaciones (Ver en Cronograma, Actividad en Línea 2): Para realizar esta actividad se requiere hacer uso de la P.A.L. (BbLearn) y su coordinación con otros compañeros para incorporare en cada grupo de trabajo se hace por medio de dicha plataforma.

1. Ingresar a la plataforma en el "área de actividades" y buscar las instrucciones para dicha actividad las cuáles abrirán según fechas del cronograma de actividades.

2. Con todos los estudiantes activos, se conformará determinado número de equipos definidos por los tutores y en cada equipo se deberán de poner de acuerdo para nombrar 1 representante que irá a negociar los acuerdos internos de cada equipo.

3. Los equipos serán listados en la plataforma para que cada miembro conozca donde está y quiénes son los demás compañeros.

4. Se construirán cuartos virtuales de reunión donde solamente podrán ingresar los integrantes de cada equipo (simulando empresas).

5. Habrá un cuarto virtual de negociaciones, donde solamente tendrán acceso los representantes previamente elegidos. En este cuarto se llevarán a cabo las negociaciones entre los representantes y donde ejecutarán los acuerdos que llevan de sus equipos, a la vez deberán tomar decisiones en el momento para concretar negocios con los demás representantes. 
6. La nota obtenida para esta actividad irá en función del alcance y logro de los objetivos establecidos para dicha actividad (ver punto 5) por cada equipo y los cuáles serán aplicados a los miembros en valor a la participación que demuestren dentro de la plataforma.

\section{AÑO 2014 (3er cuatrim.):}

Los estudiantes deberán realizar 2 actividades en línea (en BLACKBOARD LEARN) y un trabajo de campo. Todas las asignaciones se realizan en grupo, los detalles sedan según cada caso, no obstante, la conformación la realiza el estudiante con sus pares en acuerdo mutuo sin intervención de tutores.

La presentación de reportes de trabajo sigue el formato: Arial 12 y espacio interlínea de 1.5.

\subsection{Actividades en línea:}

7.1.1 Casos (Ver en Cronograma, Actividad en Línea 1): se puede realizar en grupos (máximo 3 integrantes, mínimo 2 integrantes) la extensión no debe exceder de 10 páginas. Ésta actividad se envía al profesor a través de la plataforma en el link asignado en el "área de actividades". El link abre y cierra según fechas del cronograma de actividades, una semana antes se darán las instrucciones sobre el(los) caso(s) asignado(s), entre los que vienen en los capítulos (1, 2, 3, 4, 7,10,12, 13 ó 15) del texto y esto se les hará saber mediante BbLearn. El(los) caso(s) debe(n) ser resuelto(s), manteniendo la perspectiva del área de compras, sobre los puntos enunciados en las instrucciones que se brinden.

- Estructura: La estructura de presentación estará en sección de "Materiales" BlackboardLearn para su ilustración.

- Rubrica del caso: en la misma plataforma se dejará los contenidos que serán evaluados y que deben presentar en su resolución.

7.1.2 Negociaciones (Ver en Cronograma, Actividad en Línea 2): Para realizar esta actividad se requiere hacer uso de la P.A.L. (BbLearn) y su coordinación con otros compañeros para incorporarse en cada grupo de trabajo, se hace por medio de dicha plataforma.

1. Ingresar a la plataforma en el "área de actividades buscarlas instrucciones para dicha actividad las cuáles abrirán según fechas del cronograma de actividades. Con todos los estudiantes activos, se conformará determinado número de equipos definidos por los tutores y 
en cada equipo se deberán de poner de acuerdo para nombrar 1 representante que irá a negociar los acuerdos internos de cada equipo.

3. Los equipos serán listados en la plataforma para que cada miembro conozca donde está y quiénes son los demás compañeros.

4. Se construirán cuartos virtuales de reunión donde solamente podrán ingresar los integrantes de cada equipo (simulando empresas).

5. Habrá un cuarto virtual de negociaciones, donde solamente tendrán acceso los representantes previamente elegidos. En este cuarto se llevarán a cabo las negociaciones entre los representantes y donde ejecutarán los acuerdos que llevan de sus equipos, a la vez deberán tomar decisiones en el momento para concretar negocios con los demás representantes.

6. La nota obtenida para esta actividad irá en función del alcance y logro de los objetivos establecidos para dicha actividad (ver punto5) por cada equipo y los cuáles serán aplicados a los miembros en valor a la participación que demuestren dentro de la plataforma. 


\section{ANEXO 2: Ejemplo de una de las instrucciones de la actividad colaborativa}

\section{INSTRUCCIONES PARA NEGOCIACIONES}

A continuación se indica en qué consiste esta actividad a ser desarrollada en línea (es importante remarcar que TODO debe quedar con evidencias, es decir, las negociaciones internas, para ponerse de acuerdo en las acciones a tomar, deben estar reflejadas en el área de "intercambio de archivos y foro" de cada grupo.

Deben tener presente lo siguiente:

1. Los grupos $(1,3,5$ y 7$)$ hará el rol de "proveedores" y los otros grupos $(2,4,6$ y 8$)$ de "compradores"; independientemente del rol que jueguen, en todas las empresas habrá un representante que representará a su equipo (empresa) y serán los que ingresen a las mesas de negociaciones donde se establezcan acuerdos manejando el esquema SCOR (ver tema 3 -Material complementario 2) y además utilizando las fases y estrategias de negociación ahí plasmada, para además lograr establecer alguna metodología de trabajo de su preferencia (CPFR,VMI o ECR).

\section{Las mesas de negociación serán las siguientes:}

Mesa Negociación A: Grupo 1 y 2

Mesa Negociación B: Grupos 3 y 4

Mesa Negociación C: Grupos 5 y 6

Mesa Negociación D: Grupo 7 y 8

El profesor Alejandro estará a cargo de evaluar la Mesa $D$ con los grupos 7 y 8

La profesora Monserrat estará a cargo de evaluar las Mesas A, B, C con los grupos 1, 2, 3, 4,5 y 6

Las consultas referentes a las negociaciones se las hacen a cada profesor que les califique según el grupo que eligieron.

Ejemplo: Si usted es estudiante de Cartago y se inscribió en el Grupo 1. Su Mesa de negociación será la $A$, la profesora que debe consultar cualquier duda será en Foro de la profesora Monserrat

\section{Funciones de las empresas compradores}

Internamente las empresas COMPRADORAS deben coordinarse para jugar tres roles: 1) cliente interno o área que hace la requisición, donde se origina la necesidad del insumo a ser adquirido y que deben detallar claramente las especificaciones (presentación del insumo, cuándo lo requiere, etc.), de lo que se requiere, 2) área de compras donde se realizan las 
transacciones y gestiones para indagar información real sobre fuentes de suministro del insumo (lugar, quién vende, precio, presentaciones posibles) para luego poder tener bases para negociar con el proveedor y 3) área de almacenes, donde se debe realizar toda la coordinación en la temática de inventarios, espacios y estimar cantidades a pedir del insumo, así como fechas y horarios de recepción.

\section{Funciones de las empresas proveedoras}

Deben coordinarse para jugar tres roles: 1) Ventas o área que hace la requisición, donde se origina la necesidad del insumo a ser vendido y que deben detallar claramente las especificaciones de lo que se requiere producir o importar, 2) área de compras/producción donde se realizan las transacciones y gestiones para indagar información real sobre fuentes de suministro -descrito arriba- (si deciden comprar el insumo) o bien estimar sus costos para producir el insumo; en ambos casos será preciso estimen lotes mínimos de importación (o producción), así como toda la información necesaria para poder estimar ese dato y luego poder tener bases para negociar con el cliente, 3) área de almacenes, donde se debe realizar toda la coordinación en la temática de inventarios, espacios y estimar cantidades a despachar del insumo, así como posibles fechas de entrega.

\section{Funciones de los representantes de cada grupo:}

Los representantes irán a negociar los acuerdos internos del equipo (empresa) y buscarán como obtener márgenes importantes de ganancias en sus propios negocios. En caso de falla de comunicación de un negociador pueden proceder a solicitar cambio de negociador de grupo con el profesor respectivo.

Los profesores estaremos evaluando los foros internos, pero los representantes de grupo deberán enviar al finalizar cada parte de negociación un reporte de participación interna de cada estudiante, calificándolo de la siguiente forma:

Ejemplo:

\begin{tabular}{|c|c|c|c|c|c|c|}
\hline $\begin{array}{l}\text { Nombre } \\
\text { estudiante }\end{array}$ & $\begin{array}{l}\text { Centro } \\
\text { universitario } \\
\text { al que } \\
\text { pertenece } \\
\text { estudiante }\end{array}$ & $\begin{array}{l}\text { Rol del } \\
\text { estudiante }\end{array}$ & $\begin{array}{l}\text { Participación } \\
\text { de } \\
0 \text { a } 25 \%\end{array}$ & $\begin{array}{l}\text { Participación } \\
\text { de } \\
26 \% \text { a } 50 \%\end{array}$ & $\begin{array}{l}\text { Participación } \\
\text { de } \\
51 \% \text { a } 75 \%\end{array}$ & $\begin{array}{l}\text { Participación } \\
\text { de } \\
76 \% \text { a } 100 \%\end{array}$ \\
\hline María & 04 & Cliente & & $36 \%$ & & \\
\hline
\end{tabular}




\begin{tabular}{|l|l|l|l|l|l|l|}
\hline Pérez & (Alajuela) & interno & & & \\
Salas & & & & & \\
Nota: Es & & & & & \\
un & & & & & \\
ejemplo & & & & & \\
\hline
\end{tabular}

\section{Duración de la actividad y su estructura:}

Las negociaciones están previstas entre el $\mathbf{6}$ julio - 20 julio inclusive

Las actividades se realizarán en 4 partes durante el siguiente periodo:

\section{Parte I}

Abre: 9 julio a las 8:00 hrs

Cierra: 11 Julio a las 23:59 hrs

\section{Parte II}

Abre: 12 Julio a las 8:00 hrs

Cierra: 14 Julio a las 23:59 hrs

\section{Parte III}

Abre: 15 Julio a las 8:00 hrs

Cierra: 17 Julio a las 23:59 hrs

\section{Parte IV}

Abre: 18 julio a las 8:00 hrs

Cierra: 20 julio a las 23:59 hrs

La información de cada parte se irá dando en cada apertura con las distintas actividades a realizar

\section{Calificación:}

El total de toda la actividad en línea de Negociaciones tiene un valor porcentual de $7.5 \%$ de la nota equivaliendo esto al $100 \%$. Por lo que cada parte de negociación tendrá un valor de $25 \%$ para un total de $100 \%$ las 4 partes.

\section{Forma de entregar la información:}

Toda la información de entregas solicitadas de las distintas partes que se negociarán las deben enviar a través del link que se les pone en Actividades en línea 2 y cerrarán 
automáticamente en las fechas y horas que se les vaya indicando, en caso de no enviarlas a tiempo alguno de los grupos ya sean compradores o proveedores perderán el total de la nota de cada parte y en cada Parte se les indicará a los que entregaron a tiempo la información, cómo deben proceder en caso de que no reciban la información esperada.

Entregarán en el Link de profesora Monserrat los grupos 1, 2, 3, 4,5 y 6

Recordar que entregarán en el Link del profesor Alejandro los Grupos 7 y 8

\section{Aspectos generales de calificación:}

El informe final de notas de dicha actividad se entregará hasta 8 días hábiles después del cierre de la actividad. Aproximadamente para el 30 julio 2014. 


\section{ANEXO 3: Ilustración de los grupos de actividad "Negociaciones" (2014) en Moodle}

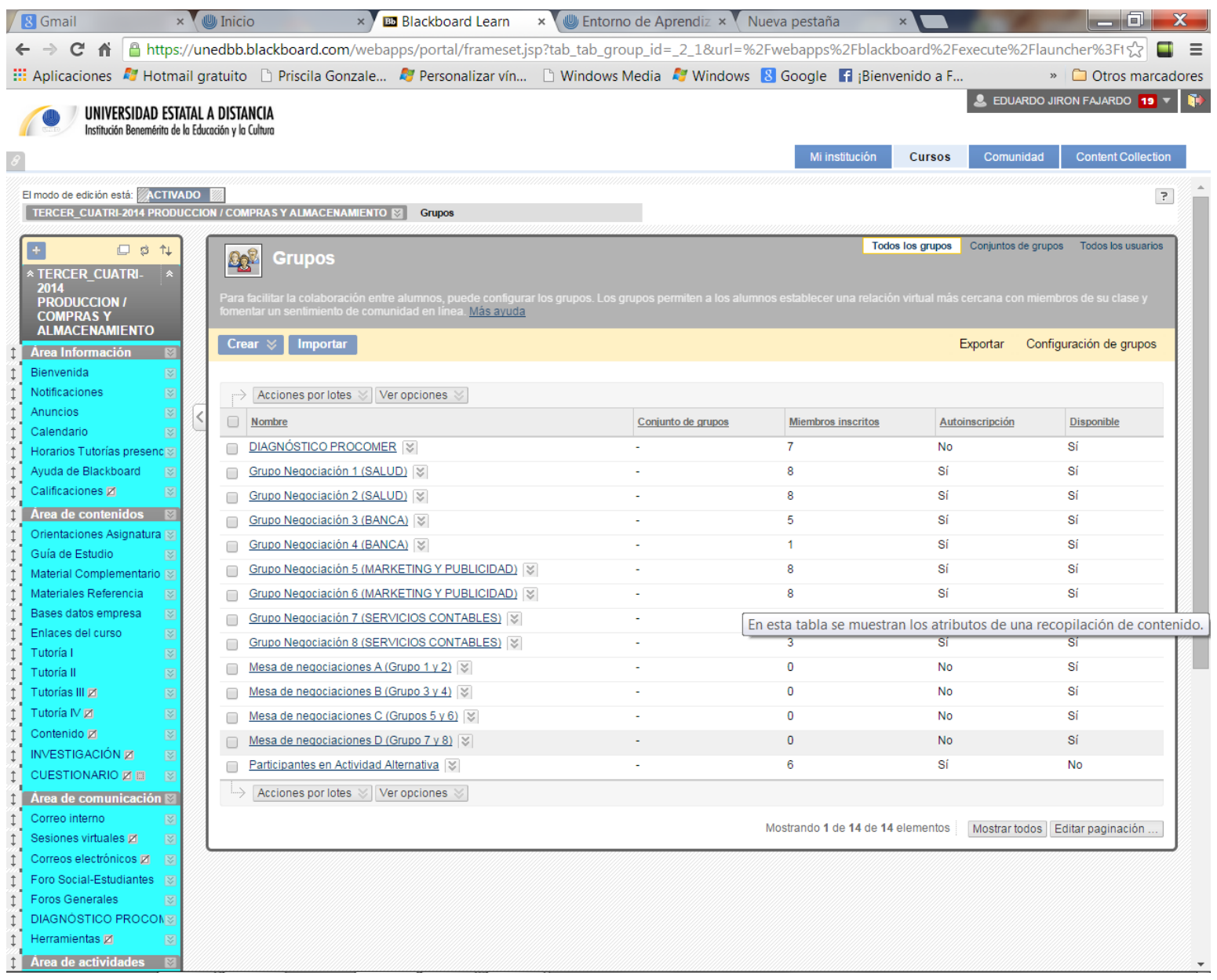

Fuente: Plataforma virtual Moodle (3er cuatrim_2015) 


\section{Anexo 4: Rúbrica utilizada para evaluar "NEGOCIACIONES" en 2012}

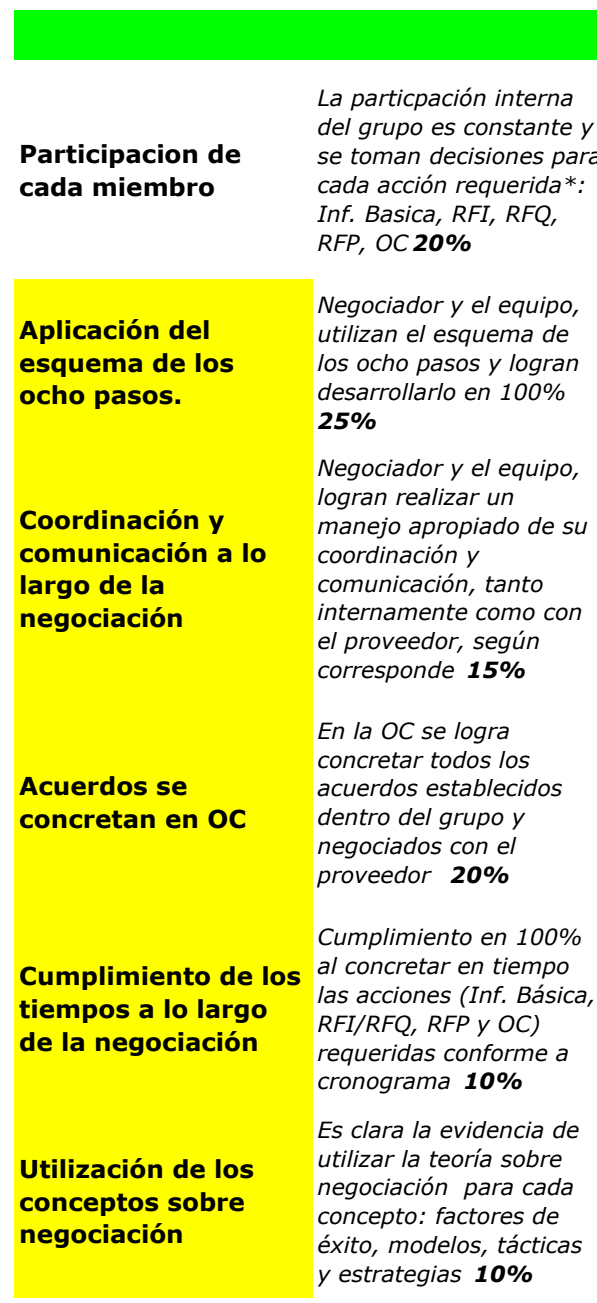

\section{NEGOCIACIONES}

La particpación interna La particpación interna del grupo es constante $y$ del grupo es poca

se toman decisiones para constante y se toman

4 de las acciones decisiones para 3 ó 2 de requeridas*: Inf. Basica, las acciones requeridas*:

$R F I, R F Q, R F P, O C 15$ Inf. Basica, RFI, RFQ, $\%$ $R F P, O C \mathbf{1 0} \%$

Negociador y el equipo, utilizan el esquema de los ocho pasos y logran desarrollarlo en más de un $75 \% \quad \mathbf{2 0} \%$

Negociador y el equipo logran realizar un

manejo aceptable de su coordinación y comunicación, tanto internamente como con el proveedor, según corresponde $\mathbf{1 0 \%}$

En la OC se logra concretar los acuerdos negociados con el proveedor $y$ parcialmente los establecidos dentro del grupo 16\%

Negociador y el equipo, utilizan el esquema de los ocho pasos y logran desarrollarlo en más de un $50 \% \quad 14 \%$

Negociador y el equipo, realizan un manejo apropiado de su coordinación " $y$ " comunicación, sólo internamente o sólo con el proveedor $\mathbf{7 \%}$

En la OC se logra concretar todos los acuerdos establecidos dentro del grupo y parcialmente los negociados con el proveedor $12 \%$

Cumplimiento en $75 \%$ al Cumplimiento en $50 \%$ al Cumplimiento en $25 \%$ al NO se realizó la actividad concretar en tiempo 3 de las acciones (Inf. Básica, $R F I / R F Q, R F P$ y $O C)$ requeridas conforme a cronograma $8 \%$

Es clara la evidencia de utilizar la teoría sobre negociación en tres conceptos: factores de éxito, modelos, tácticas o estrategias $\mathbf{1 0 \%}$

La particpación interna del grupo es muy poca y se toman decisiones para 1 o ninguna de las acciones requerida*: Inf. Basica, RFI, RFQ, RFP OC $5 \%$

Negociador y el equipo, utilizan el esquema de los ocho pasos y logran desarrollarlo en más de un $25 \% 7 \%$

Negociador y el equipo, realizan un manejo apropiado de su coordinación "O" comunicación, sólo internamente o sólo con el proveedor $3 \%$

En la OC se logra concretar parcialmente NO se colocó la OC o se los acuerdos establecidos coloca la OC pero NO dentro del grupo y contiene los acuerdos de parcialmente los negociados con el proveedor $\mathbf{6 \%}$ grupo NI los negociados con el proveedor $\mathbf{0} \%$ concretar en tiempo 2 de concretar en tiempo 1 de o NO cumplió ninguna las acciones (Inf. Básica, las acciones (Inf. Básica, entrega en tiempo de las $R F I / R F Q, R F P$ y OC) RFI/RFQ, RFP y OC) acciones requeridas (Inf.

requeridas conforme a requeridas conforme a Basica, RFI/RFQ, RFP, cronograma $\mathbf{5 \%}$ cronograma $\mathbf{3 \%}$ OC) $0 \%$

Es clara la evidencia de utilizar la teoría sobre negociación en dos conceptos: factores de éxito, modelos, tácticas o estrategias $\mathbf{1 0 \%}$
Es clara la evidencia de utilizar la teoría sobre negociación en un concepto: factores de éxito, modelos, tácticas o estrategias $\mathbf{1 0 \%}$
NO se realizó la actividad o NO se aplicó ninguno de los conceptos en las negociaciones $\mathbf{0 \%}$

Fuente: el autor 


\section{Anexo 5: Herramienta para seguimiento a NEGOCIACIONES en 2014}

INTEGRANTES GRUPO \#1

ESTUDIANTE 1

ESTUDIANTE 2

ESTUDIANTE 3

ESTUDIANTE 4

ESTUDIANTE 5

ESTUDIANTE

ESTUDIANTE 7
ESTUDIANTE 8 resumen:

Aplicación del esquema de los ocho pasos.

Coordinación y comunicación a lo largo de la

Acuerdos que se concretan dentro de grupos

y en mesas de neqociación.

Cumplimiento de los tiempos a lo largo de la

neqociación

toración de los conceptos solicitados

cuando se indica revisar texto o GE.

verdadero aporte al trabajo colaborativo en

eauinos.

\begin{tabular}{|c|c|c|c|c|c|c|c|c|}
\hline \multicolumn{7}{|c|}{ NEGOCIACIONES } & & \\
\hline $\begin{array}{l}\text { Al Martes 28/Oct } \\
(17: 00 \mathrm{hrs})\end{array}$ & $\begin{array}{l}\text { Al Jueves 30/Oct } \\
\text { (17:00 hrs) }\end{array}$ & $\begin{array}{l}\text { Al Lunes } 3 / \text { Nov } \\
(17: 00 \mathrm{hrs})\end{array}$ & $\begin{array}{l}\text { Al Miércoles 5/Nov } \\
(17: 00 \mathrm{hrs})\end{array}$ & $\begin{array}{l}\text { Al Viernes } 7 / \text { Nov } \\
\text { (17:00 hrs) }\end{array}$ & $\begin{array}{l}\text { Al Sábado 8/Nov } \\
\text { (17:00 hrs) }\end{array}$ & $\begin{array}{l}\text { Al Domingo9/Nov } \\
\text { (17:00 hrs) }\end{array}$ & & \\
\hline Inscripción individual & Elección Representante & $\begin{array}{l}\text { Uso de las } 8 \text { fases, RF's, } \\
\text { concepto disposicionn", } \\
\text { Investig-Merc, elección del } \\
\text { Esquema (VMI, ESI Inplant } \\
\text { o Posterg), criterios ABC y } \\
\text { responsab del suministro } \\
\text { (cap. 16) }\end{array}$ & $\begin{array}{l}\text { Primeros intercambios entre } \\
\text { negociadores y yel apoyo de } \\
\text { cada miembro que aporte } \\
\text { para esto. Uso } 8 \text { fases, } \\
\text { RF's. }\end{array}$ & $\begin{array}{l}\text { Haber concluido etapas } 4 \text { y } \\
5 \text { de las } 8 \text { fases, uso de los } \\
\text { RF's. Consideración del } \\
\text { esquema (VMI, ESI, Inplant } \\
\text { o postergación), rcriterios } \\
\text { ABC y tema de entregas } \\
\text { (cap. 9) }\end{array}$ & $\begin{array}{l}\text { Haber concluido etapas } 6 \text { y } \\
7 \text { de las } 8 \text { fases, uso de los } \\
\text { RF's. Consideración del } \\
\text { esquema (VMI, ESI, Inplant } \\
\text { o postergación) y tema de } \\
\text { entregas (cap. 9) }\end{array}$ & $\begin{array}{l}\text { Haber concluido etapas } 8 \\
\text { uso de los RF's. } \\
\text { Generación documento } \\
\text { (Ord. Compro contrato) } \\
\text { Implicito el esquema } \\
\text { (vMI, ESI, Inplant o } \\
\text { postergación), criterios } \\
\text { ABC y tema de entregas } \\
\text { (cap. 9) }\end{array}$ & TOTAL & $\%$ \\
\hline 0,5 & 1 & 1 & 1 & 0 & 0 & 0 & 3,5 & $46,7 \%$ \\
\hline 0,5 & 1 & 1 & 1 & 1 & 0,75 & 1,75 & 7 & $93,3 \%$ \\
\hline 0,5 & 1 & 1 & 1 & 0 & 0 & 0 & 3,5 & $46,7 \%$ \\
\hline 0,5 & 1 & 1 & 1 & 0,75 & 0,5 & 1,5 & 6,25 & $83,3 \%$ \\
\hline 0,5 & 1 & 1 & 1 & 1 & 0,75 & 1,75 & 7 & $93,3 \%$ \\
\hline 0,5 & 0 & 0 & 1 & 0 & 0 & 0 & 1,5 & $20,0 \%$ \\
\hline
\end{tabular}


Anexo 6: Ejemplos de información que elaboran en los equipos durante la actividad Requerimiento de material quirúrgico para un hospital en NEGOCIACIÓNES-2014

\section{Cirugía General}

\begin{tabular}{|c|c|}
\hline 1. & $\begin{array}{l}\text { Apósito Quirúrgico Adhesivo 2x2 cm paquetes de } 6 \\
\text { unidades. }\end{array}$ \\
\hline 2. & Bolsa De Órganos transparente 200 unidades \\
\hline 3. & Catéteres \#18. 50 unidades. \\
\hline 4. & $\begin{array}{l}\text { Fijador Externo Para Fractura Facial mediano, pequeño y } \\
\text { grande. } 100 \text { unidades. }\end{array}$ \\
\hline 5. & $\begin{array}{l}\text { Férulas Para Extremidades, Inflable Y No Inflables. Por } \\
\text { categoría para niño, adolescente y adulto. } 100 \text { unidades. }\end{array}$ \\
\hline 6. & Grapas Para Piel Removibles en cajas de 100 unidades. \\
\hline 7. & $\begin{array}{l}\text { Malla Quirúrgica pequeña, mediana y grande. } 100 \\
\text { unidades. }\end{array}$ \\
\hline 8. & $\begin{array}{l}\text { Prótesis E Implantes: de Barbilla, Esofágica, Mamaria. } 50 \\
\text { unidades de cada uno. }\end{array}$ \\
\hline 9. & Grapas cajas de 50 unidades \\
\hline 10. & $\begin{array}{l}\text { Hemoconcentradores: uso pediátrico BC } 20 \text { plus, niños y } \\
\text { adultos BC } 60 \text { plus y peso mayor de } 70 \mathrm{~kg} \mathrm{BC} 140 \text { plus. } 20 \\
\text { unidades. }\end{array}$ \\
\hline 11. & Pulverizador de CO2: hasta 200 litros. \\
\hline 12. & $\begin{array}{l}\text { Bolsas Respiratorias: pequeña, mediana y grande. } 200 \\
\text { unidades de cada tamaño. }\end{array}$ \\
\hline 13. & $\begin{array}{l}\text { Bisturís: } 5 \text { y } 4 \text {. Escalpelos: de tipo fijo de acero inoxidable } \\
200 \text { unidades. }\end{array}$ \\
\hline 14. & Clamps de aluminio. 100 unidades. \\
\hline 15. & $\begin{array}{l}\text { Curetas: de acero inoxidable con vértice flexible de ángulo } \\
\text { 90. } 50 \text { unidades. }\end{array}$ \\
\hline 16. & $\begin{array}{l}\text { Estiletes: con hojas de } 10 \mathrm{~cm} \text { puntiagudo, de acero } \\
\text { inoxidable. } 25 \text { unidades. }\end{array}$ \\
\hline
\end{tabular}




\begin{tabular}{|l|l|}
\hline 17. & $\begin{array}{l}\text { Pinzas: adson de } 12 \mathrm{~cm} \text {, anotómica y quirúrgica , Pinza } \\
\text { auricular Hartmann } 8,5 \mathrm{~cm} 30 \text { unidades }\end{array}$ \\
\hline 18. & $\begin{array}{l}\text { Porta Agujas: Castroviejo y Anillos dorados. } 200 \text { unidades } \\
\text { de cada una. }\end{array}$ \\
\hline 19. & Separadores: modelo RIBBON 30 unidades. \\
\hline 20. & Sondas Acanalada: $13 \mathrm{~cm}$ Acero Inoxidable 50 unidades \\
\hline 21. & $\begin{array}{l}\text { Tijeras: de disección de manga corta tipo roma, hilo de } \\
\text { manga corta puntiaguda. } 150 \text { unidades }\end{array}$ \\
\hline 22. & Trocar oshcner $14.0 \mathrm{co}, 6.5 \mathrm{~mm}$ \\
\hline 23. & Dermatomos de $75 \mathrm{~mm}$ y $50 \mathrm{~mm} 100$ unidades de cada uno. \\
\hline
\end{tabular}

Continuación Anexo 6:

Factura de una empresa de carnes en NEGOCIACIÓNES-2011

\begin{tabular}{|c|c|c|c|}
\hline \multicolumn{2}{|r|}{$\begin{array}{ll}\text { FORMA DE PAGO } \\
\text { Crédito: } & \square \\
\text { Contado: } & \square\end{array}$} & \multicolumn{2}{|c|}{$\begin{array}{l}\text { T.árnicos GLIRIA'S Gourmet } \\
\text { Teléfono: (506) 2527-2376 } \\
\text { Fax: (506) 2527-2300 } \\
\text { Sn Pedro, Mtes. Oca, Sn Carlos, Sn Vito } \\
\text { Correo electrónico: ej@gloriasgourmet.co.cr }\end{array}$} \\
\hline \multicolumn{2}{|r|}{ Pedido $N^{\circ}:$ O/C \# 111} & \multicolumn{2}{|c|}{ Factura \#154649873 } \\
\hline $\begin{array}{l}\text { Cantidad } \\
\text { en kilos }\end{array}$ & Descripción & \begin{tabular}{c|c} 
Precio \\
unitario
\end{tabular} & Precio \\
\hline 10 & SALCHICHÓN PRIMERA CALIDAD, SIN CHILE & $1.700,00$ & $17.000,00$ \\
\hline 15 & BISCTEC DE PUNTA DE LOMO DE CORTE DELGADO & $4.500,00$ & $67.500,00$ \\
\hline 10 & LENGUA DE VACA/RES & $5.000,00$ & $50.000,00$ \\
\hline 20 & CHULETA DE CERDO DE CORTE MEDIANO (SIN PELLEJO) & $5.500,00$ & $110.000,00$ \\
\hline 20 & CHICHARRONES DE CERDO & $6.000,00$ & $120.000,00$ \\
\hline 15 & CABEZA DE CERDO SIN OJOS & $2.500,00$ & $37.500,00$ \\
\hline 10 & CARNE TITIQUEÑ A ( EN TROZOS) & $3.500,00$ & $35.000,00$ \\
\hline 20 & CARNE DE LOMO DE RES (VA PICADO EN TROZOS MEDIANOS) & $5.250,00$ & $105.000,00$ \\
\hline 15 & MONDONGO DE RES (VA PICADO) & $3.250,00$ & $48.750,00$ \\
\hline 20 & LOMO DE RES EN BISTEC & $4.750,00$ & $95.000,00$ \\
\hline & & & \\
\hline & TOTAL (colones) & & 68575000 \\
\hline \multicolumn{2}{|c|}{ Cheque a favor de CÁRNICOS GLORIA'S GOURMET } & \multicolumn{2}{|l|}{ RUC \# 5-465465-46544 } \\
\hline \multicolumn{2}{|c|}{ Observaciones: Crédito 15 días a partir de recepción pedido } & & \\
\hline
\end{tabular}


Trabajo colaborativo entre estudiantes por medio de una plataforma tecnológica Eduardo Jirón Fajardo 


\section{Continuación Anexo 6:}

Factura de una empresa de mantenimiento a flota vehicular en NEGOCIACIÓNES-2011

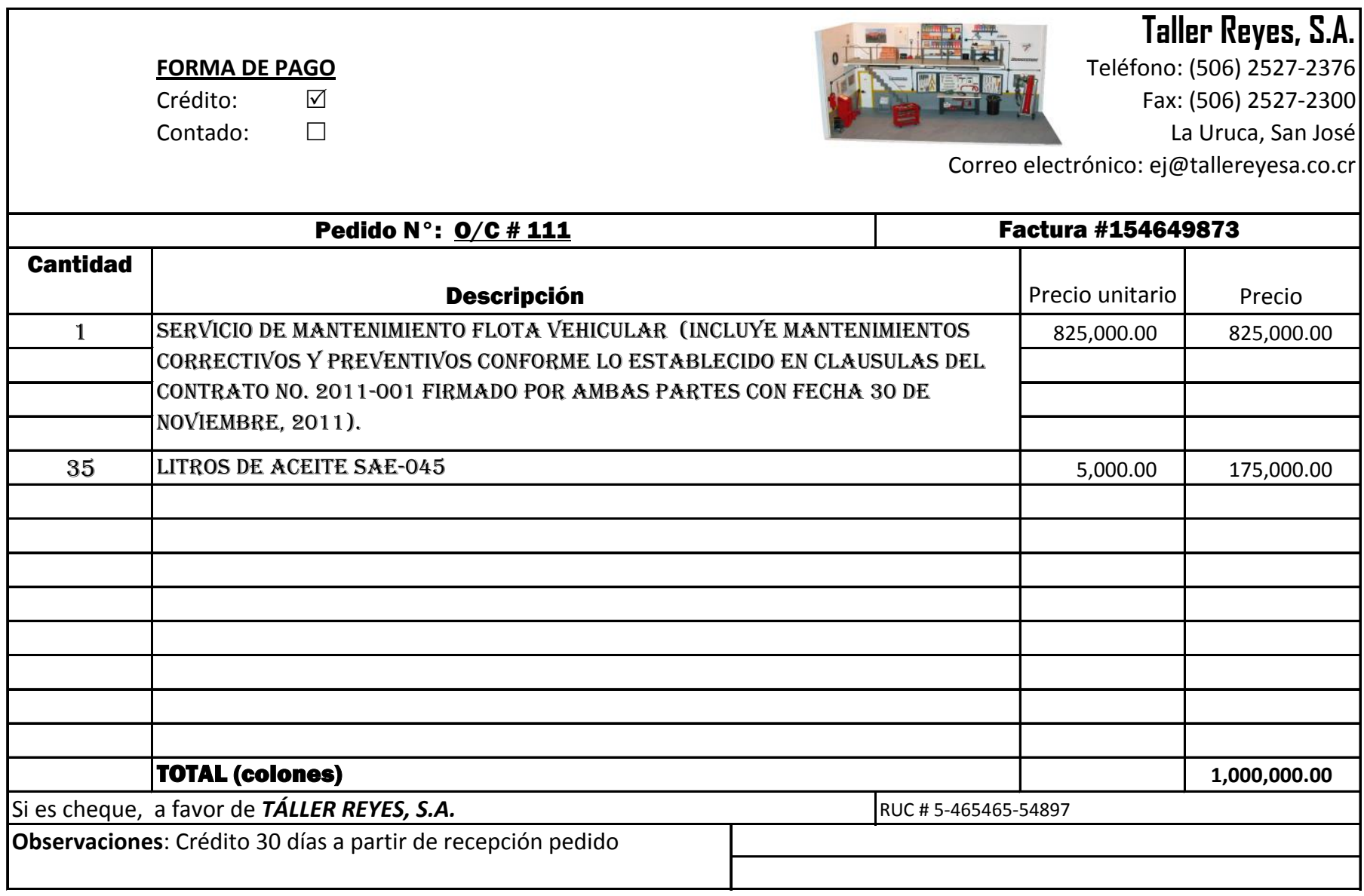




\section{Anexo: 7 Dinámica interna de un grupo en NEGOCIACIONES-2013}

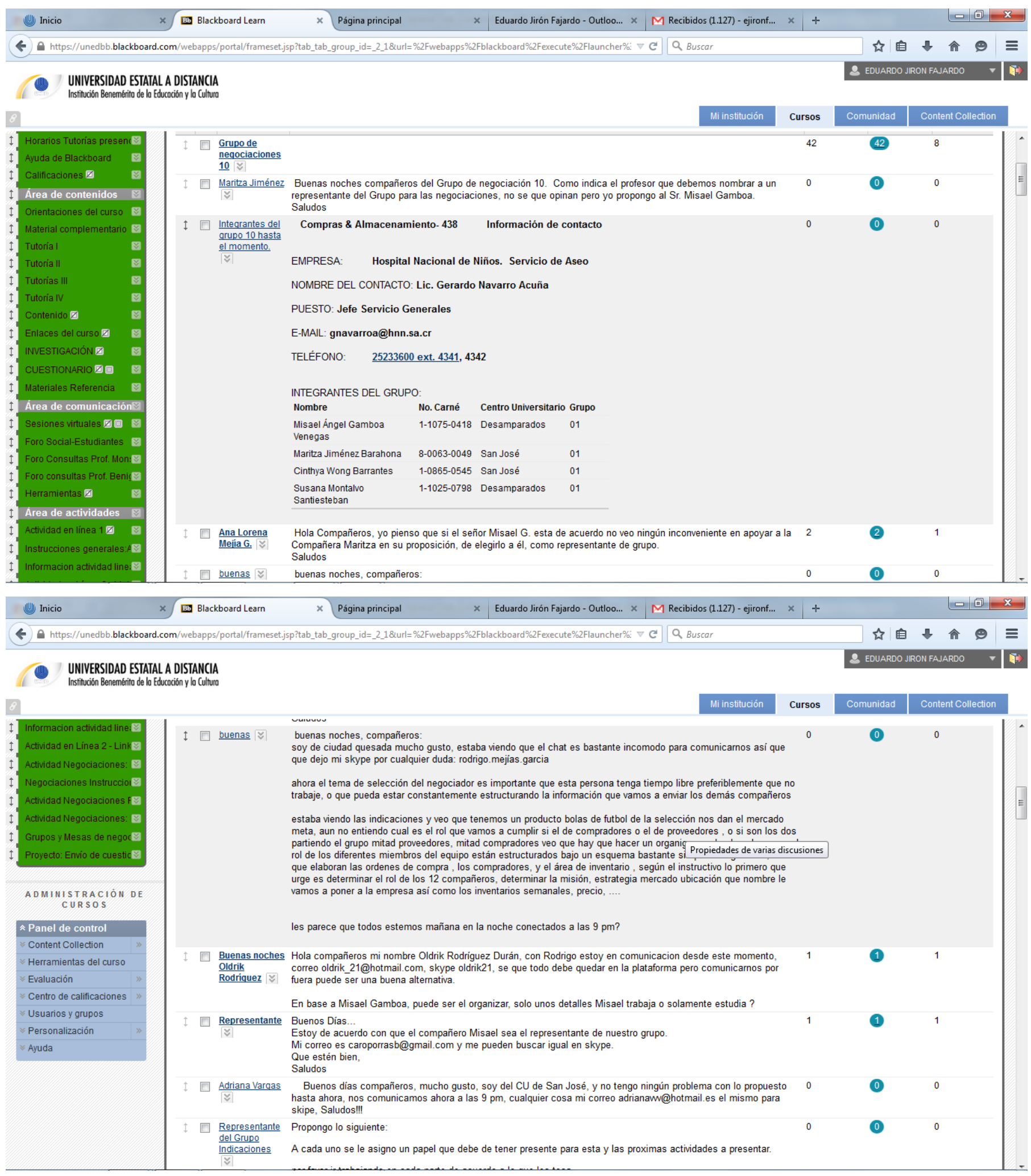




\section{Continuación Anexo 7:}

\section{Intercambio de archivos dentro de un grupo}

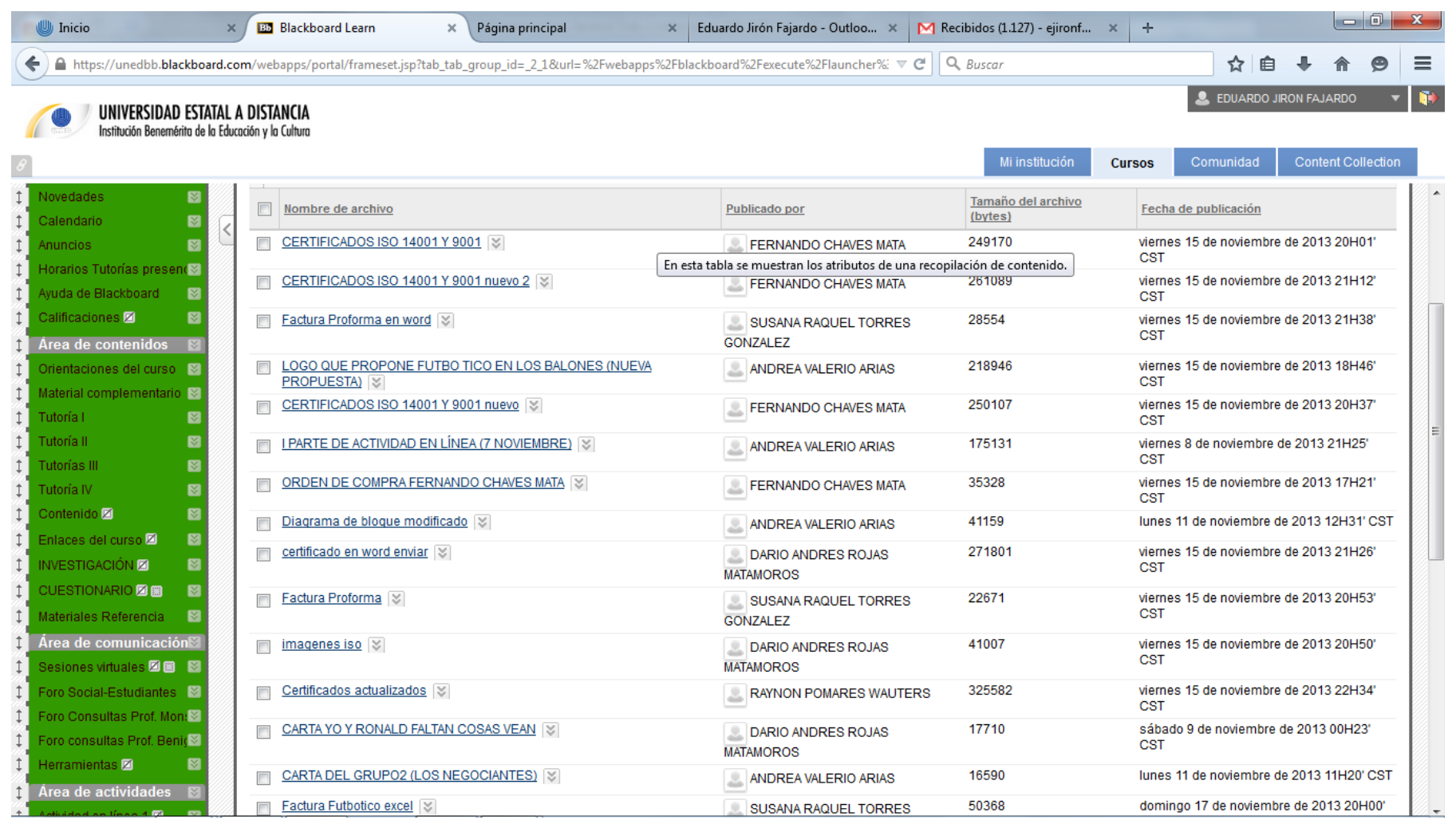

\section{Búsqueda de maneras para lograr mejor coordinación en actividad}

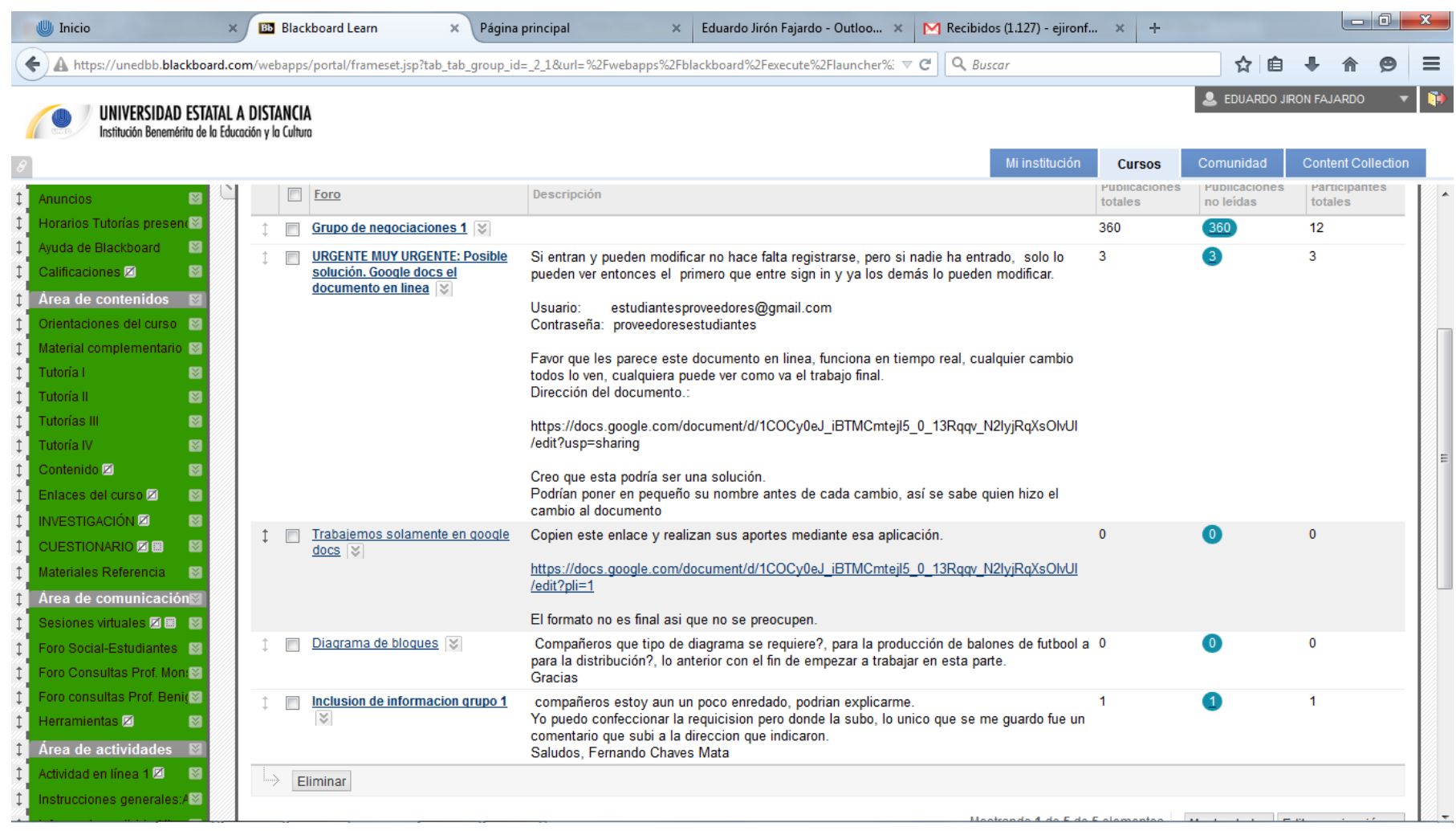




\section{Anexo 8: Intercambio de información de mesas de negociación (2013)}

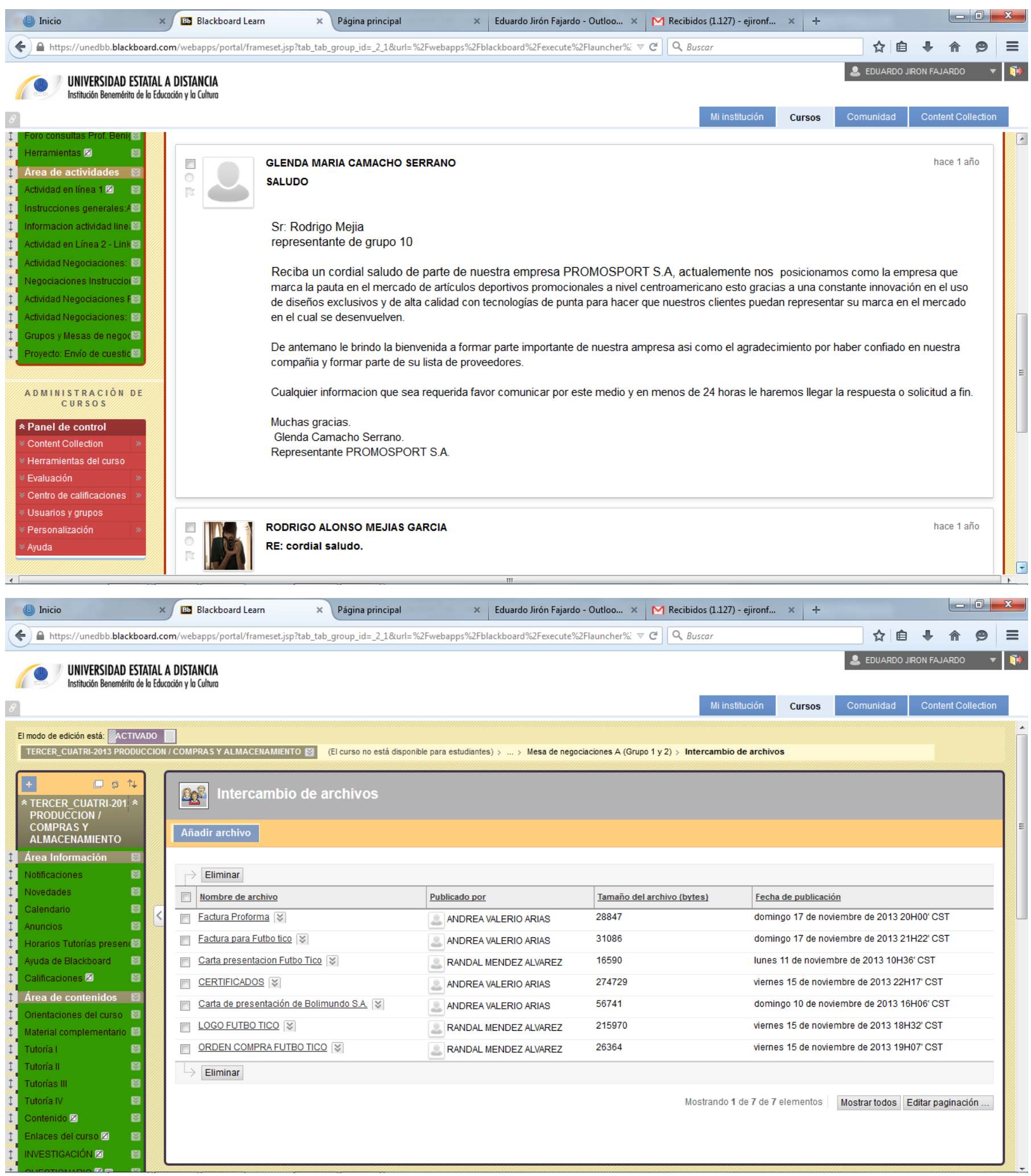

